\title{
Cumhuriyet İdeolojisinin Kentteki İzini Sürmek; Yeşilgiresun Gazetesinde Kültür, Mekan, Anlam
}

\author{
Özgür Demirkan ${ }^{1}$ \\ ORCID: 0000-0001-5430-1018
}

\author{
Selin Karaibrahimoğlu² \\ ORCID: 0000-0002-0941-8185
}

Öz

Bu çalışmanın amacl; Cumhuriyet ideolojisinin periferide konumlanmış bir kent olarak Giresun kent mekanındaki izlerini aramaktır. Kente ve mimariye özgü her düşünme eylemi ve uygulama; merkez eksenli ideolojik yaklaşımların yanı sıra kentlerin kültürleri, coğrafyaları ya da yerel aktörlerinden beslenmektedir. Giresun da, Anadolu kentlerinin genelinde gözlenen ideoloji eksenli modernleşme sürecini yerel ölçekteki gelişmeler doğrultusunda yaşamış bir kenttir. Kentteki modernleşme çabaları ve uygulamaları bir taraftan merkezin öngörüleri ve ideolojisi ile biçimlenirken diğer taraftan merkezden bağımsı bir deneyim ve duyarlllkla uygulamaya konulmuş; kente özgü kültürel, ekonomik ya da coğrafi koşullar bağlaminda gerçekleşmiştir. Bu bakışla, Cumhuriyet ideolojisinin mimari ve kültürel faaliyetler üzerinden periferide yaygınlaştırılmaya çalı̧ıldı̆̆̆, imar hareketlerinin ivmelendiğgi 1930-1940 aralığı çalışmanın zamansal odağıdır. Cumhuriyet ideolojisi, Giresun kentine ve mimariye ilişkin somut semboller ve toplumsal dönüşümü ivmelendiren külttürel faaliyetler ile paralel bir biçimde okunmaya çallşılmıştır. Anadolu'nun en eski yerel gazetelerinden Yeşilgiresun Gazetesi çalışmanın odağına yerleştirilmiş, Cumhuriyet ideolojisinin kentteki izleri göstergebilimsel çözümleme yöntemi kullanılarak mekana ve kültüre ilişkin haberler üzerinden anlamlandırlmaya çalş̧ılmıştır.

Anahtar Kelimeler: Cumhuriyet ideolojisi, mekan, kültür, anlam, Yeşilgiresun Gazetesi

\footnotetext{
${ }^{1}$ Dr. Öğr. Üyesi, Giresun Üniversitesi, ozgur.demirkan@giresun.edu.tr

2 Dr. Öğr. Üyesi, Giresun Üniversitesi, selin.karaibrahimoglu@giresun.edu.tr

idealkent (c) Kent Araştırmaları Dergisi (Journal of Urban Studies)

http://idealkentdergisi.com
}

Geliş Tarihi Received Date: 15.09.2020 Kabul Tarihi Accepted Date: 14.12.2020 


\title{
Tracing the Republican Ideology in the City; Culture, Place and Meaning in Yeşilgiresun Newspaper
}

\author{
Özgür Demirkan ${ }^{3}$ \\ ORCID: 0000-0001-5430-1018
}

\author{
Selin Karaibrahimoğlu ${ }^{4}$ \\ ORCID: 0000-0002-0941-8185
}

\begin{abstract}
The aim of this study is to search for traces of the Republican ideology in the city space of Giresun on periphery. Every act of practice specific to the city is nurtured by cultures, geographies or local actors of the cities in addition to center-based ideological approaches. Giresun is a city that experienced the ideology-based modernization process observed in general in Anatolian in parallel with the developments at local scale. While the modernization efforts and practices in the city were shaped by the predictions and ideology of the center, they were put into practice with an experience and sensitivity independent from the center. The period of 19301940, during which attempt was made to spread the Republican ideology to the periphery through architectural and cultural activities, were determined as the temporal focus of the study. The ideology was read parallel with concrete symbols of Giresun city, and architecture and cultural activities that accelerate social transformation. Yeşilgiresun, which is one of the oldest local newspapers of Anatolia, was placed in the focus of the study, and effort was given to interpret the traces of the Republican ideology in the city through news about place and culture by using the semiotic analysis method.
\end{abstract}

Keywords: Republican ideology, place, culture, Yeşilgiresun Newspaper

\footnotetext{
${ }^{3}$ Asts. Prof., Giresun University, ozgur.demirkan@giresun.edu.tr

${ }^{4}$ Asts. Prof., Giresun University, selin.karaibrahimoglu@giresun.edu.tr

idealkent @ Kent Araştırmaları Dergisi (Journal of Urban Studies)

http://idealkentdergisi.com
}

Geliş Tarihi Received Date: 15.09.2020 Kabul Tarihi Accepted Date: 14.12.2020 


\section{Giriş}

Cumhuriyetin ilanının ardından il statüsü kazanan Giresun zamanla, tarımsal üretim üzerinden gelişimini sürdüren küçük bir Osmanlı kazasından modern kent düzeninin gereği ve Cumhuriyet ideolojisinin nesnesi olarak bankalar, eğitim yapıları, sağlık kurumları, parklar ve meydanlar gibi yeni yapıların ve mekansal düzenlemelerin yer almaya başladığı bir kente dönüşmüştür. Kentte gerçekleştirilen sanatsal ve kültürel faaliyetler kentteki modernleşme deneyimini desteklemiş, özellikle halkevleri tarafından düzenlenen konferans, müsamere, sinema ve tiyatro etkinlikleri modern yaşamın içselleştirilmesinin ve yaygınlaştırılmasının aracı olmuşlardır. Bu dönemde kentte modernleşme ideolojisinin mekan ve kültür ortakllğında hayata geçirildiği ve devamlılığının sağlandığı söylenebilir. Bu çok yönlü ortaklık çalışma yönteminin belirlenmesinde etkili olmuş, kente ve mimariye ilişkin somut ideolojik semboller ve toplumsal dönüşümü ivmelendiren kültürel faaliyetler aynı zamansal düzlemde okunmaya çalışılmıştır. Cumhuriyet ideolojisini merkez kentlerin mimarlık yazını üzerine konumlandıran çalışmaların dışında, periferi odaklı araştırmaların kent ve mimarlık tarihi yazınına eklenmesine ve döneme ilişkin kavrayışın zenginleştirilmesine katkı sağlanmıştır. Modern mimarlık mirası kapsamına dahil edilen yapılar üzerinden yürütülen dönemsel okumalarda sıklıkla karşılaşılan biçim odaklı anlayışa, mekan ve kültür ortaklığında farklı anlamsal çıkarımlara zemin hazırlayan çoklu bir bakış açısı kazandırılmıştır.

Çalışmada, Cumhuriyet ideolojisinin Giresun kentindeki güzergahını belirlediği modernleşme süreci hem Anadolu'nun en eski yerel gazetelerinden, hem de kent tarihine kaynaklık eden en önemli arşivlerinden biri olarak Yeşilgiresun Gazetesi üzerinden okunmuştur. Yerel gazeteler söz konusu dönemde kente, kentliye ve mimariye ilişkin söylemleri ile aslında okuyucusuna bilgi ulaştıran en etkili iletişim araçları arasındadır. Bir taraftan okuyucusunun, dolayısıyla toplumun dilini güçlendirirken diğer taraftan uluslararası engelleri zorlayarak merkeziyetçiliğe yarar sağlamış, temel kuralları ve gelenekleri denetlemeye ve bildirmeye yardımcı olmuşlardır (Mora, 2008, s.3). Bu özellikleriyle gazeteler herhangi bir statü ayrımı gözetmeksizin herkesin evine ulaşarak toplumsal bir bilinç yaratma, sosyal yaşamı etkileme ya da egemen ideolojiyi yayma etkisine sahiptirler. Dolayısıyla yerel gazete arşivlerini bir kentin yaşamına, toplumsal düzenine ve imarına ilişkin bilgi sahibi olmanın, kent gelişimini okuyabilmenin bir aracı olarak kabul etmek mümkündür. 
Bu kapsamda çalışmanın amacı, Cumhuriyet'in ilanıyla Anadolu'yu yeniden inşa etmeye başlayan ideolojinin periferide konumlanmış bir kent olarak Giresun kent mekanındaki izlerini Yeşilgiresun Gazetesi üzerinden aramaktır. Çalışmanın zamansal odağı; Anadolu'daki modernleşme sürecini konu alan çalışmalarda sıklıkla takip edilen dönemsel değerlendirmelerde Anadolu modernleşmesinin ikinci dönemi ${ }^{5}$ olarak kabul edilen 1930-40 aral1ğıdır. Söz konusu dönem somut gereksinimler ile düşünsel arayışların kesiştiği, ekonomik gerçeklikle toplumsal yani kollektif duygulanımların bütünleştiği, siyasal erkin ideolojisi bağlamında toplumla ilişkili pek çok alanda moderni nesnelleştirdiği bir dönemdir. Benzer şekilde Giresun'un kent ve mimarlık tarihinde de Cumhuriyet ideolojisinin yaygınlaştırılmaya çalışıldığı, dolayısıyla insan odaklı dönüşümün çarpıcı izlerini taşıyan ve ideolojik geri dönüşümlere sahne olan bir dönem olarak önem kazanmaktadır. Bu bağlamda 1930-40 aralığında Yeşilgiresun'da yer alan haberler taranmış, mekan ve kültür odaklı haber başlıkları seçilerek yayın tarihlerine göre kronolojik düzende sıralanmışlardır. Mekan ve kültür ortaklığındaki ilişkisel bir okuma için göstergebilimsel çözümlemeyle haberler anlamlandırılmaya çalışılmış, ideolojinin kentteki mekansal izleri aranmıştır. Dolayısıyla öncelikle Cumhuriyet ideolojisi, toplum ve kültürle kurduğu ilişki ve bu ilişkinin somutlaştığ yer olarak mekanla etkileşimi tartışılmalıdır.

\section{Cumhuriyet İdeolojisi, Kent ve Mimarlık}

Politik bir alan olarak düşünüldüğünde mekanın, çeşitli aktörlerin dolaylı ya da dolaysız etkisi ile varlık bulduğu, mekanı yaratan ve tasarlayanlar kadar iktidar ve kullanıcıların da bu fiziksel çevrenin oluşumunda belirleyici oldukları görülmektedir. İktidarların işleyiş biçimleri ve ideolojik yöntemleri düşünüldügüunde, ideolojiyi kuran tüm aktörler mekan üzerinden varlık kazanmakta (Aydınlı, 1996, s.28), sistemin kendini meşrulaştırma çabasının ürünlerine dönüşmektedirler. Mimarlık ve kent planlama ise tarihsel süreç içerisinde toplumsal gelişmelerden, sosyo-ekonomik koşullardan ya da ideoloji eksenli gelişmelerden en çabuk etkilenen disiplin olarak iktidarın ideolojisini, bilgisini, mesajını yansıtan politik bir sembol oluşturma sorumluluğu taşımaktadır. Egemen ideolojilerin kendisini ve süreçlerini bireylerine anlamlı

\footnotetext{
${ }^{5}$ Türk modernleşmesi; Sıkılgan/Utangaç Modernite (1850-1923), Köktenci/Radikal Modernite (19231950), Popülist Modernite (1950-1980) ve Modernite Projesinin Aşınması (1980-halen) dönemleri üzerinden incelenir (Bkz. Tekeli, 1998, s.19). Ayrıca, 1930, inkılapların ana hatlarıyla tamamlandığı, uygulamaların yoğunlaştığı bir dönemi işaretler (Bkz. Tüfekçioğlu, 1992, s.54.).
} 
gösterme çabasının aracı olarak mimarlık, ideoloji ve politika ilişkisini Tanyeli şu şekilde açıklar; "Alışılagelmiş historiyografik yaklaşım odur ki, önce ideoloji ve siyaset zemininde tanımlar ortaya konur sonra da mimarlık bunları temel alarak mekanlar kurar". İdeolojiler her zaman mimari ile forma bürünerek toplum içindeki bireylerle kurduğu istemsiz etkileşim üzerinden varlığını hissettirmeye, kendi mimari düzenlerini ortaya koymaya, uygulamaya ve en nihayetinde dayatmaya eğilimli olmuşlardır (Tanyeli, 2015, s.30, 32). Toplumun üretmiş olduğu mekanlar çeşitli sosyal değişimlerle kendini yeniden var ederken, iktidar tarafından üretilen mekanlar siyasal ve sosyal ilişkilerin birlikte ürettiği tarihsel bir süreç içerisinde varlık gösterirler (Avar, 2019, s.9). Bu noktadan bakıldığında, ideolojinin ya da devlet eliyle inşa edilen yapıların, bireylerin ve kamusal ortaklıkların ürettiği yapılara göre boyutsal ve sembolik açıdan daha güçlü ve ezici nitelikler taşıdıkları söylenebilir (Erzen, 2016, s.20). Kent mekanında, -mimari mekandan anıtlara kadar- iktidarın imzasını taşıyan yapıların her biri, bir taraftan iktidar ideolojisini yansitan politik semboller olarak varlık kazanırken diğer taraftan mimarlık ve ideoloji arasındaki çarpıcı ilişkinin izlenmesine olanak sağlar. Dolayısıyla, Cumhuriyet' in ilk yıllarında Anadolu'da uygulanan imar faaliyetleri ve mekansal düzenlemelerin taşıdıkları özellikler ile ideolojinin zeminini dolduran semboller olarak anlamlandırılması mümkündür.

Mimari, Cumhuriyet ideolojisinin sergilendiği bir sahne olarak öne çıkarken yasalarla desteklediği kendi mimari düzenini bu sahnede uygulamaya koymuştur (Karaibrahimoğlu, Usta, 2018, s.47). Böylece çok sayıda öncü kamusal mekân modeli geliştirilerek rasyonel, kolektif ve devlet merkezli bir modernleşme anlayışı yaşama geçirilmiştir. Öyle ki kentlerde inşası planlanan kamusal yapılar ve kentsel donatılar bir "toplum projesi" olarak modernleşme ve bireyi ulusun bir üyesi haline getirme ideali ile ilişkilidir (Tanyeli, 1998, s.103). Aynı amaçla halkevleri ve köy enstitüleri, halkın kültürel gelişimini ve eğitimini hedefleyen kurumlar olarak açılmış (Yeşilkaya, 1999, s.36), kültür ve sanat etkinlikleri ideolojiyi görünür kılan uygulamalar olarak kabul edilmiştir.

Cumhuriyet ideolojisi, öncelikle yeni bir kimlik yaratmak, sonrasında sosyal yapıyı değiştirmek ancak bu yenileşme sürecinde toplumun varlığını ve kültürünü koruyarak devam ettirmek, bunun üzerinden yeni, kolektif ve milli bir kimlik aramak üzerine kurgulanmıştır (Karpat, 2019, s.318). Cumhuriyet ideolojisini temellendiren modernleşme devrimleri, mimari yapılardan kentlere, eğitim sisteminden yasalara kadar ısrarla uygulanmaya çalışılmış, 
toplumsal anlamda bir değişim ortamı yaratılmış; yeniden şekillenen sosyolojik ve ekonomik faaliyetler hem mimari uygulamalar hem de kültür ve sanat etkinlikleri için önemli bir alan yaratmıştır. Bozdoğan'a göre, bu yıllarda "şeylerin" biçimini değiştirmek için harcanan zaman ve enerji, Cumhuriyete özgü görsel bir modernlik kültürünün üretilmesine, denetlenmesine ve yaygınlaştırılmasına odaklanmıştır (Bozdoğan, 2008, s.74). Bu nedenle Anadolu'nun merkezinden periferisine, her köşesinde yürütülen inşa faaliyetleri ve kültürel faaliyetler Cumhuriyet ideolojisini ve öğretilerini halka birebir ileten ve yeni bir yaşam biçimini anlatan etkinlikler olarak bir bütünün parçaları gibi okunmalıdır. Bu ideolojik bütün, periferi kentlerinin kültürel ve coğrafi özelliklerinin yarattığı mekansal farklılıklara karşın Mardin (2009)'in tanımladığı şekilde "kendi simgesel birikimlerinden beslenen bir çoğunluk" yaratmaktadır. Bu kentlerde yerellikle beslenen, aynı zamanda yeni ideoloji ve düşünce sistemi üzerine inşa edilmiş bir süreç izlenmiştir. Bu süreç yeni bir dilin tanımlanmasını olanaklı kılmış; inşa edilen kamu yapıları, gerçekleştirilen belediye hizmetleri ve açlan halkevleri, bu ideolojik ve kavramsal çeşitliliğin sembolü olarak sürece dahil edilmişlerdir.

Özetle, Anadolu kentlerinde izlenen mimari ve kentsel ölçekli üretimin kayda değer bir kısmının dönemin iktidar ideolojisi ile beslendiği söylenebilir. Ancak periferide yoğunlaşan mekansal ve kültürel üretimi aydınlatıcı, dönemi ve süreci açıklayıcı bilgilerin yer aldığı kaynaklara ulaşmak oldukça güçtür. Bu nedenle merkez kentler dışındaki periferi kentlerinde ideoloji, mimari ve kültür ara kesitinde konumlandırılan çalışmalar ancak yerel aktörlerden, yerel arşiv ve kayitlardan beslenerek gerçekleştirilebilmektedir. Bu bilgi kaynaklarından biri olarak yerel gazeteler tarihsel süreçte iktidar ideolojisini toplumun her kesimine ulaştıran araçlardan biri, belki de en güçlü taşıyıcısı olarak iktidarların hakim ideoloji ve söylemlerinin meşrulaştırılmasına, merkez-periferi arasında görünmez bir çekim gücünün yaratılmasına imkan sağlamaktadır. Bu nedenle çalışmanın mekansal odağı Giresun'da, Cumhuriyet ideolojisinin öngördüğü mekansal ve kültürel uygulamalar, kentin en eski yerel gazetelerinden Yeşilgiresun üzerinden anlamlandırılmaya çalışılmıştır.

\section{Yeşilgiresun'da Kültürr, Mekan, Anlam: Göstergebilimsel Çözümleme}

Sosyal bir grubun veya hareketin ortak olarak paylaştı̆̆ bir düşünce sistemini yani ideolojiyi temsil eden haber medyası, dünyaya ve olaylara karşı geliştirdiği ortak bir düşünceye ya da rehberlik edecekleri ortak fikirlere sahiptir (Van Dijk, 2009, s.127). Bu yönüyle haber medyası toplumsal iktidarın 
kurulduğu, inşa edildiği ve egemen ideolojinin sınırlarının çizildiği araçlardan biri olarak tanımlanabilir (Ayhan, 2018, s. 85; Kazancı, 2006). Bu açıdan bakıldığında gazete haberlerinin okuyucu kitlesi ile buluştuğu ortak bir ideolojik zeminden bahsedilebilir. Ancak ileti akışının söz konusu olduğu her alanda göstergeler bulunmaktadır ve medya metinlerinin de bir gösterge sistemi olarak görülmesi ve çözümlenmesi gerekmektedir (Parsa ve Parsa, 2004, s.1). Bu çözümlemelerin ana ekseni anlam arayışları üzerine kurgulanarak bir metnin ne ifade ettiği ya da ardındaki gizil bilginin ne olduğu sorgulanmaktadır. Bu nedenle göstergebilimde anlam çözümlemesi, her yerde yaşayan, her düşünce dizgesinin oluşumunda var olan bir tasarı, sürekli gelişen bir yaşama-okuma-düşünme-yeniden üretme ve yeniden anlamlandırarak var olma-var etme etkinliğidir (Rıfat, 2011, s.22).

Göstergebilim, en yalın anlamıyla kültürü iletişim açısından inceleyen bilim dalı olarak tanımlanmakta (Erkman, 1987, s.22), bir ürünün farklı anlam katmanlarına bölünmesine yardımcı olarak sınıflandırmalarda ve değerlendirmelerde yol gösterici olmaktadır (Erkaslan, 2009, s.76). Farklı bakış açılarına sahip göstergebilimsel çözümlemelerinin -içerik çözümlemesi, söylem çözümlemesi, anlatı çözümlemeleri- ortak elemanları olarak gösterenin, göstergenin ve gösterilenin ne olduğu ve birbirleriyle nasıl ilişki kurdukları belirleyici olmaktadır. Gösteren sözlü, yazılı ya da görsel bir olgu; gösterge temsiliyet gücü olan, temsil ettiğinin yerini alabilecek her çeşit nesne ya da olgu (Rufat, 2011, s.12); anlam ise gösterenin gösterilene bağlandığı bir durumu ifade etmektedir. Bu nedenle çalışmada farklı içeriklere sahip göstergebilimsel çözümleme yöntemleri arasından Saussure (2014) tarafından şematize edilen "gösteren" (signifier) ve "gösterilen" (signified) kutuplarından oluşmuş göstergebilimsel yaklaşım esas alınmıştır (Şekil 1). Yeşilgiresun Gazetesi üzerinden Cumhuriyet ideolojisinin kentteki izlerinin arandığ çalışma, anlam odaklı bir çözümleme yaklaşımı üzerine kurgulanmıştır. İdeoloji, Yeşilgiresun Gazetesi' ndeki mekan ve kültür haberlerinin gizil bilgisi olarak kabul edilmiş, göstergebilimsel çözümleme yöntemi ile anlamlandırılmaya çalışımıştır.

Bu kapsamda birbiriyle bağlantılı üç katman üzerine temellendirilen yöntemin ilk katmanı gösterenin tanımlanması ve incelenmesi üzerine kurgulanmıştır. Bir gösteren olarak Yeşilgiresun çalışmanın odağına alınmış, gazetenin yayın hayatına başladığı günden bugüne izlediği güzergah ve ideolojik etkinliği araştırılmış, Cumhuriyet ideolojisinin Anadolu'nun kültürel ve mekansal gelişiminde belirleyici olduğu 1923-1950 aralığındaki tüm sayıları ta- 
ranmıştır. Çalışmanın ikinci katmanı göstergelerin belirlenmesidir. Bu katmanda çalışmanın zamansal odağı olan 1930-40 aralığındaki sayılarında yer alan mekan ve kültür haberleri belirlenmiş ve bu haberlerin başlıkları anlamsal çözümlemenin göstergeleri olarak kabul edilerek kronolojik düzende siralanmıştır (Tablo 1). Çalışmanın sınırlandırılmasının gerekliliği resmi, dini bayram, okul müsameresi haberleri çalışma kapsamının dışında tutulmasına neden olmuştur. Çalışmanın son katmanı ise gösterilenin çözümlemesi üzerine kurgulanmıştır. Bu katmanda gazetede yer alan mekan ve kültür haberlerinin ardındaki ideoloji eksenli anlamlar gösterilen olarak çözümlenmiş (Tablo 2), kent mekanında izleri tartı̧ılmıştır.

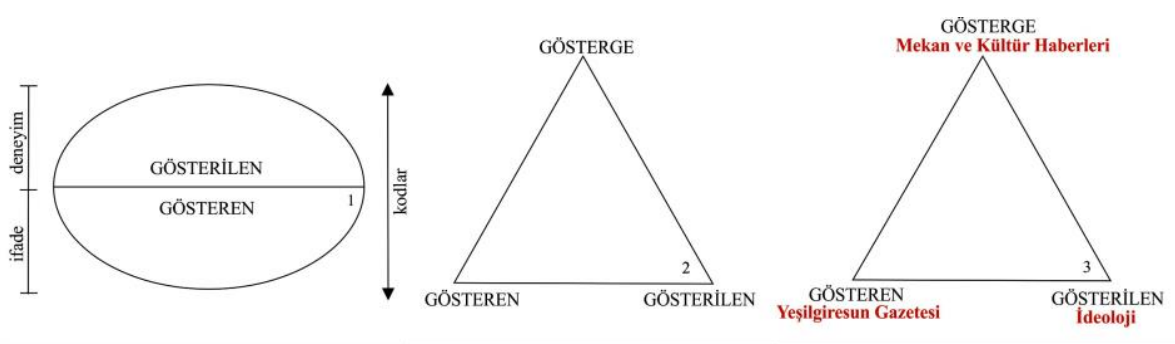

1.Saussure'ün İkili Göstergesi

2.Peirce Üçlü Göstergesi

3.Yeşilgiresun'da Göstergebilimsel Çơzümleme

Şekil 1. Pierce ve Saussure'ün göstergebilimsel çözümlemesi (Bayrakçı, 2011, s.13) ve çalışma yönteminin şematik anlatımı

\section{Gösteren Olarak Yerel Bir Gazete; Yeşilgiresun}

Yeşilgiresun Gazetesi, 100 yılı aşkın bir süredir sürdürdüğü yayın hayatı ile çoğu ulusal gazeteden bile eski bir geçmişe sahiptir (Hızlan, 2016). İlk sayıs1 1 Haziran 1925 tarihinde yayınlanan Yeşilgiresun (Öğütçü, 2019), zaman zaman yayın hayatına ara vermesine karşın yerele ilişkin tarih, kültür, siyaset, iktisat, edebiyat, spor, ulaşım, tarım gibi konularda güçlü söylemler üretmiştir. Cumhuriyetin ilk yıllarından günümüze kentin gündemini takip eden gazetenin kentin hem toplumsal, ekonomik, politik durumuna hem de fiziksel mekanının gelişimine olan tanıklığı kent belleğinin önemli bir arşivi olarak görülmesine neden olmaktadır. Bölgenin en eski gazetelerinden Işık Gazetesi'nin devamı niteliğindeki Yeşilgiresun; ilk yıllarında Arap harfleri ile basılmış, Harf İnkılabının ardından Latin harfleri ile basılmaya başlanmıştır. Anadolu genelinde yeni alfabenin yaygınlaşması, taşra kentlerinde yayınlanan dergi, gazete ve kitap sayısının istikrarlı bir şekilde artmasını ve Cumhuriyet rejimini destekleyen üst sosyal grupların ve aydınların ideolojilerini anlatabilmelerini sağlamıştır. Yeşilgiresun, bu yerel basın organlarından biri olarak Giresun'da varlık göstermiş, her dönem Atatürk inkılaplarına ve Cumhuriyet rejimine bağlı yayın politikası benimsemiştir (Çapa, 2003, s.3). 
$\mathrm{Bu}$ anlamda gazetenin iktidarın ideolojisini benimsediği, dolayısıyla yayınladığı haberler ile modernlik uygulamalarını destekler bir imaj sergilediği söylenebilir. Ancak söz konusu dönemde, modernlik konularında yazı yazmak kadar gazeteleri takip etmek ve okuma alışkanlığı kazanmak da modern bir faaliyet olarak kabul edilmelidir (Düzenli, 2009, s.93). Yeşilgiresun Gazetesi haftalık yayınlanmaya başladığı 1925'den günlük yayınlandı̆̆ 1975'e kadar kentliyi gazete okumaya yönlendirerek aynı zamanda modern bir faaliyetin aracı olmuştur. Bu nedenlerle, Cumhuriyetin ilk yıllarından günümüze kente ve çevresine ilişkin kapsamlı bilgi sunan bir arşiv olarak yerele ilişkin tarih araştırmalarına kaynaklık etmektedir.

\section{Gösterge olarak Gazete Haberleri: Yeşilgiresun'da Mekan ve Kültür}

Mekan, özellikle de kamusal mekan iktidarın ideolojisini, bilgisini ve mesajını yansıtan politik bir sembol (Lefebvre, 2014, s.75), kültür ise; ideoloji ile çok yakından ilintili, ideolojinin saygınlığını kendi mekanizmasının esaslarına dayalı olarak geliştiren bir kavram (Mardin, 2018, s.20) olarak birbirini tamamlar. Her ikisinin biraradalığı mekanın niceliksel farklılıklarını kültürün ise niteliksel farklılıklarını yok eder.

Yeşilgiresun'da 1930-1940 aralığında tarihlenmiş ve ideolojinin kentteki yazılı kanıtları olarak kabul edilebilecek haber başlıkları, toplumsal ilişki biçimlerini belirleyen unsurlar olarak mekan ve kültür ortaklığında, bütüncül bir yaklaşımla ele alınmıştır. Elbette haber başlıklarının kapsamlı ve güçlü entellektüel bir içeriğe sahip oldukları söylenemez, ancak gazetelerin rutin düzenlerinin bir parçası olarak okuyucunun detaylı bir okuma yapmaksızın gündemden haberdar olmasını sağlar (Karaibrahimoğlu, Demirkan, 2019, s.2648). Bu nedenlerle Yeşilgiresun'da yer alan mekan ve kültür haberlerinin başlıkları, aynı zaman düzlemindeki aynı ideolojinin göstergeleri olarak bütünleşik okumaya olanak sağlayacak düzende sıralanmıştır (Tablo 1). Buna göre, tablonun orta hattına dikey bir zaman çizgisi yerleştirilmiş, haberlerin yayınlanma yılları ve yayınlandıkları gazete sayıları bu çizgi üzerinde işaretlenmiştir. Zaman çizgisinin her iki yanında, mekan ve kültür haberlerinin başlıkları gazetede yer aldıkları şekilde gruplanarak yerleştirilmişlerdir. Haber başlıkları her iki sütunda içeriklerine ilişkin fotoğraflarla birlikte verilmiş, fotoğrafın ilişkili olduğu haber başlığı renklendirilmiştir. İdeoloji eksenli anlamsal çözümleme görsel alg1 düzeyinde de desteklenmiştir. 
Tablo 1. Yeşilgiresun' da mekan ve kültür haberleri (1930-1940)

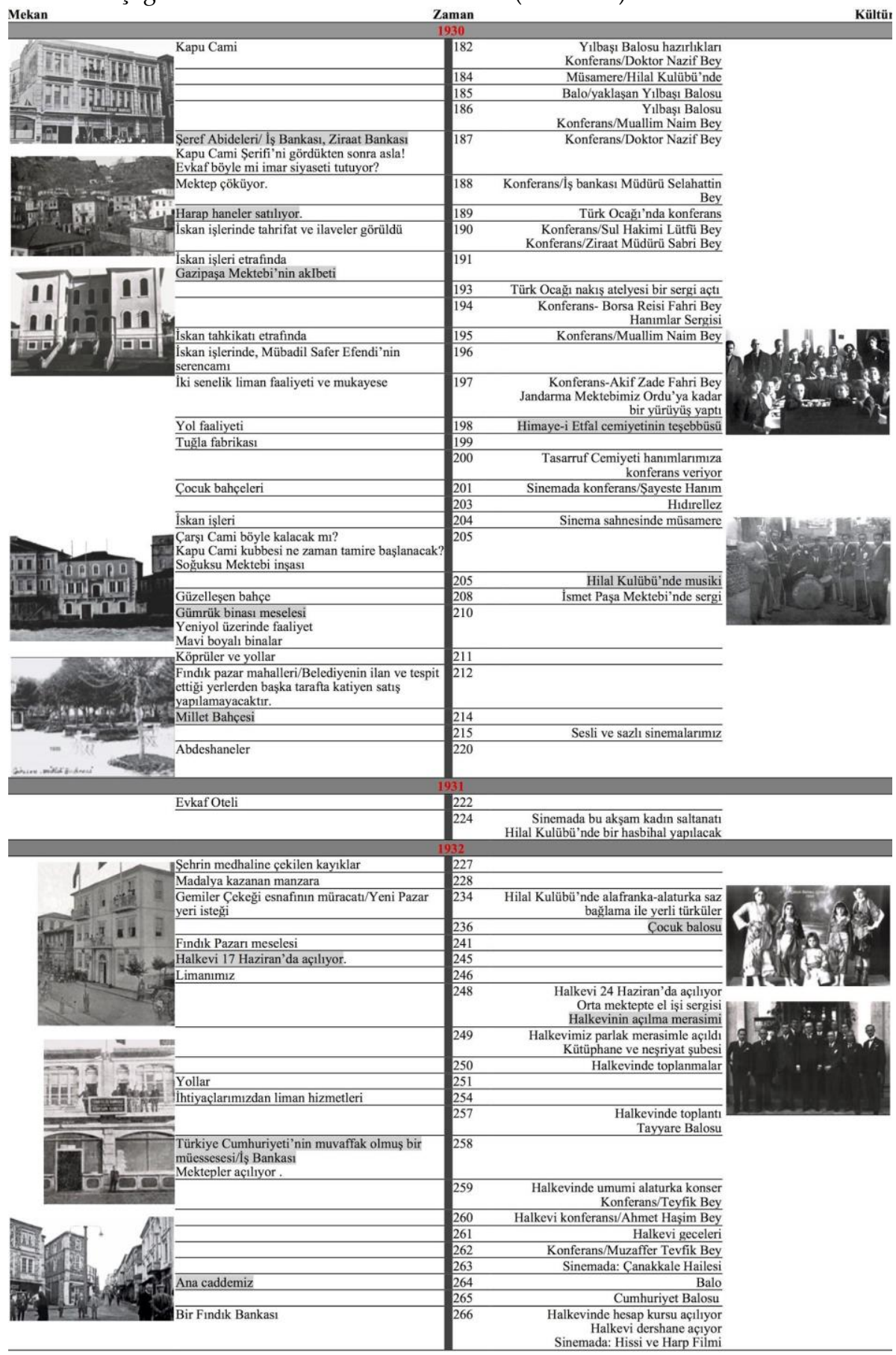




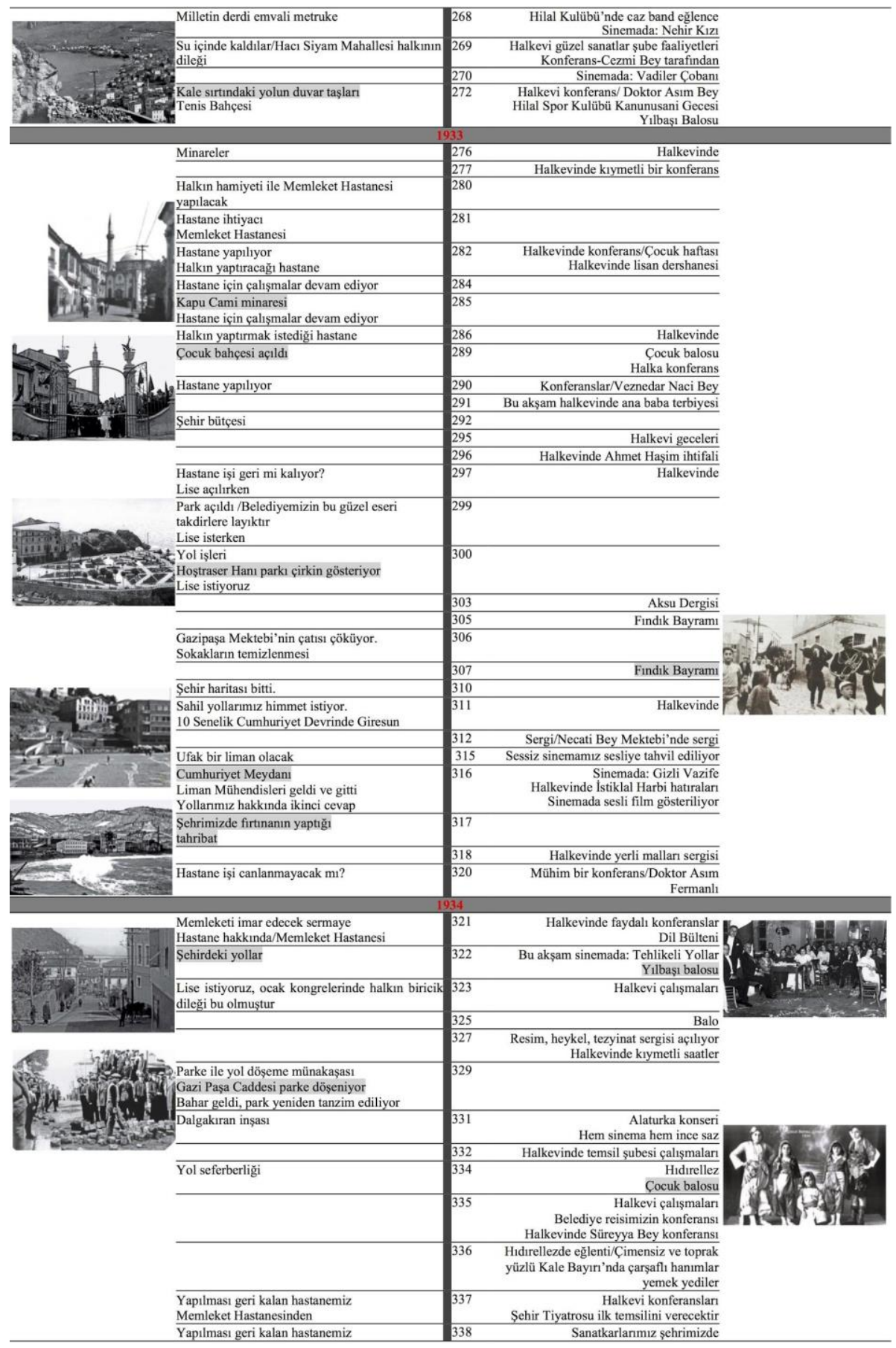




\begin{tabular}{|c|c|c|c|}
\hline$\theta$ & Yol işleri & $\begin{array}{l}\text { Mayıs Yedisi/Kalede bir Garden parti } \\
\text { Yeşiltepe Musiki Heyeti konser verdi }\end{array}$ & \\
\hline & Yapılması geri kalan hastanemiz hakkında & Garden Parti & \\
\hline & & Küçükyalı Parkı'nda bir Garden Parti & \\
\hline & Ne kadar bekleyeceğiz? & 343 & \\
\hline & $\begin{array}{l}\text { Yeniden dirilmesini istediğgimiz işimiz. } \\
\text { Yollarımız }\end{array}$ & 344 & \\
\hline & $\begin{array}{l}\text { Sahil yollarımız } \\
\text { Çocuk bahçesinde kurbağa sesleri }\end{array}$ & 345 & \\
\hline & $\begin{array}{l}\text { Belediye Reisi Essref Dizdar Bey'in gazetemize } \\
\text { beyanatt; Imar ișleri }\end{array}$ & 348 & \\
\hline & & Findik Bayramı & \\
\hline & & $\begin{array}{ll}351 & \text { Findık Bayramı; ilk sapanı Karadeniz'in } \\
\text { süvarisi bağladı }\end{array}$ & \\
\hline & & 352 Iș Bankası'nın onuncu yilı kutlamalan & \\
\hline & Bir findık laboratuvarı açlacak & Halkevinde konferans & \\
\hline & Iskele ve dalgakiran yapılacak & 412 & \\
\hline$t=$ & $\begin{array}{l}\text { Okul yapiları } \\
\text { Kaldirmlar }\end{array}$ & 413 & \\
\hline & Spor sahası istiyoruz & & \\
\hline & $\begin{array}{l}\text { Gazi Pasă Caddesi'nin parkesi bitti } \\
\text { Belediyenin güzel işleri/bakkallara camekan }\end{array}$ & 414 & \\
\hline & $\begin{array}{l}\text { Yol kaldırım çalısmalanı } \\
\text { Tamir edilen okul }\end{array}$ & 415 & \\
\hline & Gümrük binası/yeni bina ihiyac1 & 417 Kimsesizler için verilecek balo hazırllkları & \\
\hline & & Gençlik toplantıları & \\
\hline & Bir şehir halkına saldırllyor, tarziye istiyoruz. & Yılbaşı Balosu iyi geçti & \\
\hline & $\begin{array}{l}\text { Bir ilkokulu gezerken/Gazipaşa Mektebi } \\
\text { Bir şehir güzelleşiyor }\end{array}$ & $\begin{array}{l}\text { Konferanslar } \\
\text { Köyde radyo } \\
\end{array}$ & \\
\hline & $\begin{array}{l}\text { Evkaf Oteli- Cumhuriyetin evkafindan bu isimle } \\
\text { bir otel yaptrinlmasinn istiyoruz } \\
\text { Giresun'un en önemli ve önde gelen ihtiyacı: } \\
\text { kadastro }\end{array}$ & 422 & \\
\hline & & Halkevinde veda çay 1 & \\
\hline & Boztekke Okulu açilyyor & 424 & \\
\hline & Memleket hastanesinden & İkinci konferans & \\
\hline & Hastahanesiz Gireson & 427 & \\
\hline & $\begin{array}{l}\text { Cumhuriyet Alanı parke ile döşeniyor } \\
\text { Geri kalan hastanemiz }\end{array}$ & 428 & \\
\hline & Giresunumuzda lise açılmasııı istiyoruz & Halkevimiz yeni bir eser hazirliyor & \\
\hline & Güzelleșen Gireson & 435 & \\
\hline & Postane binası yapilyor & 436 & \\
\hline & Elbirliği ile memlekete hastane kazandırırız & $\begin{array}{r}\text { Yazlik sinema açilyyor } \\
\text { Gireson bahçe sineması açliyor }\end{array}$ & \\
\hline & Atatürk heykeli & 442 & \\
\hline & Yeni posta binası açıldı & 444 & \\
\hline & Karadeniz' in en zengin ve işlek iskelesi: Gireson & 446 & \\
\hline & & $\begin{array}{l}\text { Valimiz bir okuma yazma seferberliği } \\
\text { bașlattı }\end{array}$ & \\
\hline & ilimize modern bir mezbahane yapilacak & Findık Bayramı & \\
\hline & $\begin{array}{l}\text { Bir mendirek hak edemedik mi? } \\
\text { Hastane isimiz } \\
\text { Ismet Paşa ilkokulu tamir ediliyor }\end{array}$ & 454 & \\
\hline & & Kışlik sinema açıldd & \\
\hline & Gireson'da ilk kübik bina postane & Halkevi temsilleri 'Himmetin oğlu' & \\
\hline & & 37 & \\
\hline & & Satranç kulübü açıllyor & \\
\hline & Atatürk heykeli & 476 Halkevi gösteri kolunun meşkül çalıısması & \\
\hline & Lise istiyoruz & 479 & \\
\hline & & Halkevi gösteri kolu calışmaları & \\
\hline & Atatürk heykeli için 40 bin lira tahsil edildi & 482 & \\
\hline & & Kozanoğlu Piyesi 3 gece gösterildi & \\
\hline & & $\begin{array}{r}\text { Gelecek sene findık kongresi şehrimizde } \\
\text { yaplacak }\end{array}$ & \\
\hline & & Yazlik sinema & \\
\hline III II ill II II II III & Her tarafta hummalı yol çalışmalan & Yazlik sinema & \\
\hline MII i in II II II H & Gemiler Çekeği'nde rihtım & $\begin{array}{l}\text { Müstakil Ressam ve Heykeltraşlar } \\
\text { Birliği sergi açmak için müracaat etti }\end{array}$ & \\
\hline 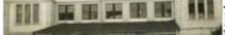 & Küçük Yalı & 490 & \\
\hline es: & Her sene kalplerimizi delen bir duygu: Lise, lise.. & 492 & \\
\hline & & $\begin{array}{r}\text { Halkevi temsilleri: Canavar Açıkhava } \\
\text { sahnesinde gösterilecek }\end{array}$ & \\
\hline & Hastanesiz Giresun & Findık Bayramı & \\
\hline & & Findik Bayramı & \\
\hline
\end{tabular}




\begin{tabular}{|c|c|c|c|c|}
\hline & $\begin{array}{l}\text { 14. Yıldönümünũ kutlarken Gireson ve } \\
\text { çevresinde bir yıl içinde yapılan işler } \\
\text { Atatürk heykeli-Kıymetli Ressam Mahmud } \\
\text { Cüda'nın iştraki ile }\end{array}$ & 508 & Tiyatro geliyor & \\
\hline & & 513 & Halkevi temsilleri: Canavar & \\
\hline & & 38 & & \\
\hline & Din abidelerimiz güzelliklerini kaybediyor & 518 & & \\
\hline & & & $\begin{array}{r}\text { Ayşe Opereti ikinci defa temsil ediliyor } \\
\text { Ar Sunar Tiyatro Heyeti }\end{array}$ & \\
\hline & & 520 & $\begin{array}{r}\text { Halkevi çalıșmaları; edebi bir gece } \\
\text { Konferans-Fındık Istasyonu Müdürü } \\
\text { Hakkı Mahir } \\
\text { Istanbul Opereti geliyor } \\
\end{array}$ & \\
\hline & & 521 & $\begin{array}{r}\text { Balo } \\
\text { "Yalnız Bir Kelime" Halkevi Gösteri } \\
\text { Kolu bize unutulmaz saatler yaşattı } \\
\text { Istanbul Operati șehrimizde }\end{array}$ & \\
\hline & Į̇ mahallelere kadar belediyemizin imar faaliyeti & 522 & $\begin{array}{r}\text { Tiyatro ve sahne } \\
\text { Sair Can geldi } \\
\text { Propaganda filmleri }\end{array}$ & \\
\hline & $\begin{array}{l}\text { Hacı Miktat Cami hakkında } \\
\text { Ortaokula bir pansiyon ihtiyacı vardır }\end{array}$ & 523 & $\begin{array}{r}\text { Halkevlerinin yıldönümü, } 24 \text { Halkevi } \\
\text { daha açılıyor } \\
\text { Le Rosaire'in Temsili münasebetiyle } \\
\text { bir sanat gecesi yaşadık }\end{array}$ & \\
\hline & & 525 & $\begin{array}{r}\text { Konferans-Bahriye Aliyaver Gökdeniz } \\
\text { Findık filmi }\end{array}$ & \\
\hline & & 526 & $\begin{array}{c}\text { Kızilay Balosu } \\
\text { Model Uçak Kursu } \\
\end{array}$ & \\
\hline & $\begin{array}{l}\text { Modern hastane ve ilkokul yapılırken } \\
\text { Sokaklar çamurdan geçilmiyor }\end{array}$ & 527 & $\begin{array}{r}\begin{array}{r}\text { Halkevinde konferans } \\
\text { Sümer Orkestrası }\end{array} \\
\end{array}$ & \\
\hline in: & $\begin{array}{l}\text { Hastanenin temelleri atılırken } \\
\text { Bir okul inşası eksiltmeye çıkarılırken } \\
\text { Ah lise }\end{array}$ & 528 & $\begin{array}{r}\text { Balo } \\
\text { Konferans/lktisad Vekaleti Koordinatörü } \\
\text { Ali Çamlıca }\end{array}$ & \\
\hline & Yükselen eserler karșısında & 529 & & \\
\hline & & 530 & $\begin{array}{r}\text { Valimizin riyasetinde Kızılay Balosu } \\
\text { Büyük Sinan ihtifali }\end{array}$ & \\
\hline & & 531 & Sinan'ın ölümünün 350. Yıldônümü & \\
\hline & Hastane ve mektep yapilırken & 532 & Kulüp gecesi, gençlerimiz için & \\
\hline & & 534 & $\begin{array}{r}\text { Konferans/íktisad Vekaleti Koordinatörü } \\
\text { Ali Camlıca }\end{array}$ & \\
\hline & Park açıldı. Bahçe sineması da açılıyor & 535 & & \\
\hline & $\begin{array}{l}\text { Kutlu gün hastanenin temel atma töreni yüzlerce } \\
\text { halkın iștirakiyle yapıldı } \\
\text { Yeni eserler/Çitlakkale Köprüsü }\end{array}$ & 536 & & \\
\hline & Bazı yerler șehrin temizlik ve güzelliğini bozuyor & 537 & & \\
\hline & & 538 & Sergi/Necati Bey Ilkokulu & \\
\hline Ein & $\begin{array}{l}\text { Büyük ilkokulun temel atma töreni bugün } \\
\text { yapilıyor }\end{array}$ & 539 & $\begin{array}{r}\text { Halkevimiz temsil kolu faaliyet birdenbire } \\
\text { durdu }\end{array}$ & \\
\hline & $\begin{array}{l}\text { Cumhuriyet Meydanı Anıtı/Cumhuriyet } \\
\text { Meydan'nı süsleyecek bu anitın bir an } \\
\text { evvel yapılmasını dileriz }\end{array}$ & 541 & & \\
\hline & Köprülerimiz yapılıyor & 544 & & \\
\hline & Atatürk Anıtı'nın yeri & 545 & & \\
\hline & & 551 & Güzel sanatlar ve halkın kulağı & \\
\hline & & 553 & Dil Bayramı & \\
\hline & & 554 & Balo gelecek haftaya eklendi & \\
\hline & Gireson'da eski tiyatro & 555 & $\begin{array}{r}\text { Halkevi kitap saray } 1 \\
\text { Balo } \\
\text { Tiyatro geliyor } \\
\end{array}$ & \\
\hline & $\begin{array}{l}\text { Gireson'da eski tiyatro } \\
\text { Bir şehir kulübü ihtiyacı }\end{array}$ & 556 & 22 kişilik büyük bir tiyatro heyeti geliyor. & \\
\hline & $\begin{array}{l}\text { Şehir kulübü için duyduğumuz ihtiyaçlara } \\
\text { halkevi cevap veriyor mu? }\end{array}$ & 557 & & \\
\hline & 15 yıl içinde Giresun'da vücuda gelen hizmetler & 558 & & \\
\hline & & 39 & & \\
\hline & & 567 & Halkevi gösteri kolu faaliyete geçiyor & \\
\hline 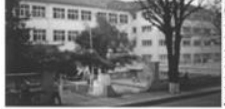 & $\begin{array}{l}\text { On dershaneli modern okul } \\
\text { Denizbank'tan iskelemizin tamirini } \\
\text { istiyoruz } \\
\text { Fındık bölgesi köylüleri: Birlik } 60 \text { bin } \\
\text { liraya modern bir kırma fabrikası yaptırıyor }\end{array}$ & 568 & $\begin{array}{r}\text { Halkevi bu akșam ilk toplantısını } \\
\text { konferans salonunda yapıyor }\end{array}$ & \\
\hline & $\begin{array}{l}\text { Istimlak edilen binalar yikıliyor } \\
\text { Cumhuriyet Aniti yapiliyor }\end{array}$ & 569 & Halkevi geceleri & \\
\hline & & & $\begin{array}{r}\text { Halkevleri bayramda konferans salonunda } \\
\text { büyük bir müsamere verecek } \\
\text { Halkevlerinin yıldönümü saat: } 20 \text { de } \\
\end{array}$ & \\
\hline$\Rightarrow$ & $\begin{array}{l}\text { S ehir işleri, elektrik tesisatın buharla işler } \\
\text { makinelere tahvir edemez miyiz? }\end{array}$ & 575 & & \\
\hline & $\begin{array}{l}\text { ISkele parası } \\
\text { Şehrin imarında el birliği, Valimiz Kalebayırı' na } \\
\text { bir otomobil yolu yaptırmaya karar verdi }\end{array}$ & 582 & & \\
\hline
\end{tabular}




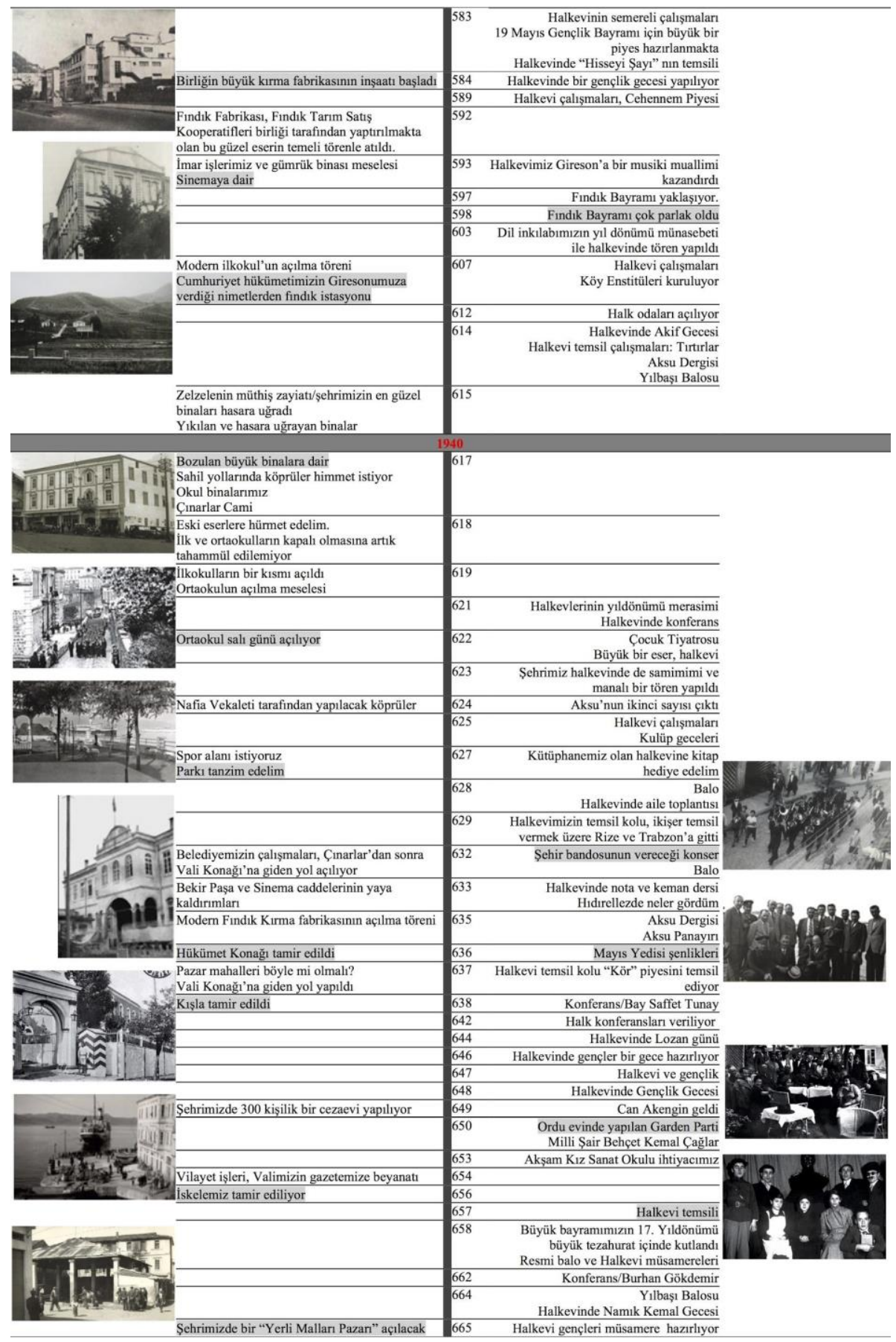




\section{Gösterilen Olarak İdeoloji: Yeşilgiresun Gazetesi'nde Anlam}

Araştırmaya konu edilen dönemde Yeşilgiresun Gazetesi'nde yer alan kentin mekansal ve kültürel gelişimine ilişkin haberlerin büyük çoğunluğu kentte olup bitene ilişkin bilgi vermenin ötesinde Cumhuriyet ideolojisinin öngördüğü düzeni halka sunmaktadır. Bu bakış açısıyla haber başlıklarının ardındaki anlamlar ideoloji ekseninde irdelenmiştir. Cumhuriyet ideolojisinin modern bir ulus kimliği yaratmak, kültürel özüne bağlı ancak ekonomik anlamda bağımsız, pozitivist bilimin üstünlüğüne inanan bir düzen oluşturma amacıyla belirlediği hedeflerin yansımaları olan ideolojik anlamlar açığa çıkarılmaya çalışılmıştır (Tablo 2). Sonrasında, bu anlamların Giresun kent mekanını ne ölçüde etkilediği, hangi mekansal gelişimin ya da kültürel etkinliklerin hangi yıllarda etkili olduğu, mekansal müdahalelerin ve kültürel faaliyetlerin hangi yıllarda dengeli bir dağılım gösterdiği dikkate alınarak Cumhuriyet ideolojisinin kent mekanındaki izleri tartısılmıştır. Son olarak, mekan/kültür haberlerinin benzerlikleri ve çeşitlilikleri ekseninde ideolojinin zamansal değişimleri anlamsal çıkarımları üzerinden anlatılmıştır (Tablo 3).

Tablo 2. Yeşilgiresun'da mekan/kültür haberlerinin ideolojik anlamlar

IDEOLOJIKK ANLAM/MEKAN

\begin{tabular}{|c|c|c|}
\hline 1930 & $\begin{array}{l}\text { İktisadi kalkınma (187/1.197.199.201/1) } \\
\text { Modern/Güzel kent yaklaşımı (182.187/2.187/3.189. } \\
\text { 190.195. 196. 205/1.205/2.208. 210/3. 214) } \\
\text { Eğitimde modernleşme (188.191/2.205/3) } \\
\text { Ulaşımda modernleşme (198.211) } \\
\text { Modern/Sağlıklı kent yaklaşımı (201.204. 210/2.220) } \\
\text { Yerel kalkınma (212) }\end{array}$ & $\begin{array}{l}\text { Toplumsal dönüşümü (182/1.184.185.186/1) } \\
\text { Halkın Eğitimi/Pozitivist bilimin üstünlüğü } \\
(182 / 2.186 / 2.187 .188 .189 .190 / 1,190 / 2.194 .195 .197 / 1.200 .201) \\
\text { Toplumsal birlik/Ulusal kimlik }(197 / 2.198 .203) \\
\text { Yeni bir yaşamın göstergeleri }(193.204 .205 .208 .215)\end{array}$ \\
\hline 1931 & Modern işlevler ve mekansal çeşitlilik (222) & Yeni bir yaşamın göstergeleri (224) \\
\hline 1932 & $\begin{array}{l}\text { İktisadi kalkınma (246.254.258.266/1.266/2) } \\
\text { Modern kent yaşamı (227.228.272/1.264) } \\
\text { Eğitimde modernleşme (258/2) } \\
\text { Ulaşımda modernleşme (251) } \\
\text { Modern/Sağlıklı kent yaklaşımı (269) } \\
\text { Yerel kalkınma (234.241) } \\
\text { Modern sosyal yaşam düzeni }(272 / 2)\end{array}$ & $\begin{array}{l}\text { Toplumsal dönüşümü } \\
(234.236 .257 / 2.259 / 1.261 .264 .265 .268 / 1.272 / 2.272 / 3) \\
\text { Halkın Eğitimi/Pozitivist bilimin } \\
\text { üstünlüğü(248/1.248/3.249/1.249/2.250. } \\
257 / 1.259 / 2.260 .262 .266 / 1.266 / 2.269 / 1,269 / 2.272 / 1) \\
\text { Yeni bir yaşamın göstergeleri }(248 / 2.263 .266 / 3.268 / 2.270) \\
\text { Millileşme/Milli kültür (269) }\end{array}$ \\
\hline 1933 & $\begin{array}{l}\text { İktisadi kalkınma }(292.315 .316 / 2) \\
\text { Modern/Sağlıklı kent yaklaşımı }(289.300 .306 / 2.316 / 3.317) \\
\text { Modern/Güzel kent yaklaşımı(276.285/1.300/2.310) } \\
\text { Eğitimde modernleşme }(297 / 2.303 / 3.306 / 1) \\
\text { Ulaşımda modernleşme (311) } \\
\text { Sağlıkta modernleşme } \\
(280.281 / 1.281 / 2.282 / 1.282 / 2.284 .285 / 2.286 .290 .297 / 2.320) \\
\text { Kollektif temsili ideoloji }(311 / 2.316) \\
\text { Devletin kimlik inşası (311) }\end{array}$ & $\begin{array}{l}\text { Toplumsal dönüşüm (289/1.295) } \\
\text { Halkın Eğitimi/Pozitivist bilimin üstünlüğü } \\
(276.277 .282 / 1.282 / 2.286 .289 / 2.290 .291 .296 .297 .311 .320) \\
\text { Yeni bir yaşamın göstergeleri } \\
\text { (295.312.315.316/1.312/2.316/3.318) } \\
\text { Toplumsal birlik/Ulusal kimlik (305.307) } \\
\text { Millileşme/Milli kültür (303) }\end{array}$ \\
\hline 1934 & $\begin{array}{l}\text { İktisadi kalkınma (321.331) } \\
\text { Modern/Güzel kent yaklaşımı (329/3) } \\
\text { Modern/Sağllklı kent yaklaşımı (322.329/1.329/2.345/2) } \\
\text { Eğitimde modernleşme (323) } \\
\text { Ulaşımda modernleşme (331.334.338/2.344/2.345) } \\
\text { Sağlıkta modernleşme (321/2.337/1.337/2.338.339.343.344) } \\
\text { Yerel kalkınma (353) } \\
\text { Devletin kimlik inşası (348) }\end{array}$ & $\begin{array}{l}\text { Toplumsal dönüşüm }(322 / 2.325 .331 / 1.334 / 2.338 .339 / 2.340) \\
\text { Halkın Eğitimi/Pozitivist bilimin üstünlüğü } \\
(321.323 .327 / 2.332 .335 / 1.335 / 2.335 / 3.337 / 1.353) \\
\text { Yeni bir yaşamın göstergeleri (322/1.331/2.327/1.337/2.352) } \\
\text { Toplumsal birlik/Ulusal kimlik (334/1.349.351) } \\
\text { Millileşme/Milli kültür (321/2.336) }\end{array}$ \\
\hline
\end{tabular}




\begin{tabular}{|c|c|c|}
\hline 1935 & $\begin{array}{l}\text { İktisadi kalkınma (417) } \\
\text { Modern/Güzel kent yaklaşımı(413/2.414/1.414/2.415) } \\
\text { Eğitimde modernleşme (413/1.415) } \\
\text { Ulaşımda modernleşme (412) } \\
\text { Modern sosyal yaşam düzeni }(413 / 3)\end{array}$ & $\begin{array}{l}\text { Toplumsal dönüşüm (417) } \\
\text { Halkın Eğitimi/Pozitivist bilimin üstünlüğü (418) }\end{array}$ \\
\hline 1936 & $\begin{array}{l}\text { İktisadi kalkınma (446) } \\
\text { Modern/Güzel kent yaklaşımı (421/2.435) } \\
\text { Modern/Sağlıklı kent yaklaşımı(451) } \\
\text { Eğitimde modernleşme (421.424.430.454/3) } \\
\text { Ulaşımda modernleşme (454) } \\
\text { Sağlıkta modernleşme (426.427.428/2.441.454/2) } \\
\text { Modern işlevler ve mekansal çeşitlilik (422/1.436.444.463) } \\
\text { Kollektif temsili ideoloji (442) } \\
\text { Devletin kimlik inşası(422) }\end{array}$ & $\begin{array}{l}\text { Toplumsal dönüşüm (419.423) } \\
\text { Halkın Eğitimi/Pozitivist bilimin üstünlüğü } \\
(421 / 1.426 .430 .448) \\
\text { Yeni bir yaşamı göstergeleri (421/2.441.457.461) } \\
\text { Toplumsal birlik/Ulusal kimlik (451) }\end{array}$ \\
\hline 1937 & $\begin{array}{l}\text { Modern/Güzel kent yaklaşımı (490) } \\
\text { Eğitimde modernleşme (476.492) } \\
\text { Ulaşımda modernleşme (487.489) } \\
\text { Sağlıkta modernleşme (496) } \\
\text { Kollektif temsili ideoloji (476.482.508/2) } \\
\text { Devletin kimlik inşası (508) }\end{array}$ & $\begin{array}{l}\text { Halkın Eğitimi/Pozitivist bilimin üstünlüğü (475.485) } \\
\text { Yeni bir yaşamın göstergeleri } \\
(476.481 .483 .486 .487 .489 .495 .508 .513) \\
\text { Toplumsal birlik/Ulusal kimlik (496) }\end{array}$ \\
\hline 1938 & $\begin{array}{l}\text { Modern/Güzel kent yaklaşımı (518 .523) } \\
\text { Eğitimde modernleşme (523/2.527/1.528/2.539) } \\
\text { Sağlıkta modernleşme (527/1.528/2.528/2.536/1) } \\
\text { Ulaşımda modernleşme (536/2.544) } \\
\text { Modern/Sağlıklı kent yaklaşımı (522.527.537) } \\
\text { Modern sosyal yaşam düzeni (535.556/1.557) } \\
\text { Kollektif temsili ideoloji (541.545) } \\
\text { Devletin kimlik inşası (558) }\end{array}$ & $\begin{array}{l}\text { Toplumsal dönüşüm }(521 / 1.526 / 1.528 / 1.530 / 1.532 .554 .555 / 2) \\
\text { Halkın Eğitimi/Pozitivist bilimin üstünlüğü } \\
(520 / 2.523 / 1.525 / 1.526 / 2.527 / 1.528 / 2.534 .539 .555 / 1) \\
\text { Yeni bir yaşamm göstergeleri } \\
(519.520 / 1.520 / 3.521 / 2.521 / 3.522 . \\
523 / 2.525 / 2.527 / 2.538 .551 .555 / 3.556 / 2) \\
\text { Toplumsal birlik/Ulusal kimlik (530/2.531) } \\
\text { Millileşme/Milli kültür (553) }\end{array}$ \\
\hline 1939 & $\begin{array}{l}\text { İktisadi kalkınma (568/2.582/1.593/1) } \\
\text { Eğitimde modernleşme (568/1.607) } \\
\text { Modern/Sağlıklı kent yaklaşımı (582/2) } \\
\text { Modern/Güzel kent anlayışı }(569 / 1.615 / 1.615 / 2) \\
\text { Yerel kalkınma (568/3.575.584.592.607/2) } \\
\text { Modern sosyal yaşam düzeni }(593 / 2) \\
\text { Kollektif temsili ideoloji (569/2) } \\
\text { Devletin kimlik inşası (607) }\end{array}$ & $\begin{array}{l}\text { Toplumsal dönüşüm }(569.614 / 4) \\
\text { Halkın Eğitimi/Pozitivist bilimin üstünlüğü } \\
\text { (567.568.571.583/1.607.614/1) } \\
\text { Yeni yaşamın göstergeleri (583/2.583/3.584.589.593.614/2) } \\
\text { Toplumsal birlik/Ulusal kimlik }(597.598 .607) \\
\text { Millileşme/Milli kültür }(603.612 .614 / 3)\end{array}$ \\
\hline 1940 & $\begin{array}{l}\text { İktisadi kalkınma (656) } \\
\text { Ulaşımda modernleşme }(617 / 2.624) \\
\text { Eğitimde modernleşme }(617 / 3.619 / 1.619 / 2) \\
\text { Modern/ Sosyal yaşam düzeni }(627 / 1) \\
\text { Modern/Güzel kent yaklaşımı } \\
(617.617 / 4.618 .627 / 2.633 .636 .638) \\
\text { Yerel kalkınma (635.637/1) } \\
\text { Devletin kimlik inşası (649.654) }\end{array}$ & $\begin{array}{l}\text { Toplumsal dönüşüm } \\
(623.625 / 2.628 / 1.632 .650 / 1.658 / 2.664 / 1.665) \\
\text { Halkın Eğitimi/Pozitivist bilimin üstünlüğü } \\
(621.622 / 2.625 / 2.627 .628 / 2 . \\
629.633 / 1.638 .642 .644 .646 .647 .648 .653 .657 .662 .664 / 2) \\
\text { Yeni bir yaşamın göstergeleri }(622.635 / 2.637 .649 .650 / 2 .) \\
\text { Toplumsal birlik/Ulusal kimlik }(633.636 .658 / 1) \\
\text { Millileşme/Milli kültür }(624.635 / 1.635 / 1)\end{array}$ \\
\hline
\end{tabular}

Modern, güzel kent yaklaşımı; Anadolu kentlerinde Cumhuriyet'in modern kentler oluşturma idealleri paralelinde tüm kentin planlanmasına yönelik sürdürülen planlama çalş̧malarını "güzel kent" anlayışı şekillendirmiştir (Tekeli, 1998, s.3). Bu kapsamla pek çok kentin gelişimini yönlendirecek şehir haritaları hazırlanmıştır. Giresun için de bir harita hazırlanmış, ancak çok kapsamlı değişikliklere yer verilmemiştir. Kentin bütününü kapsayacak bu haritanın hazırlanması gazetede önemli ve sevindirici bir gelişme olarak anlatılmıştır. Haritanın Giresun'un modern bir görünüm kazanmasının anahtarı olarak görüldüğü, kentin planlı gelişimini denetleyecek ve modernleşmenin sürdürülmesini sağlayacak bir araç olarak önemsendiği haberler üzerinden okunabilmektedir. Temizliğin ve düzenin yanı sıra güzelliğin ve modern 
kültürün temsili olarak görülen kentlerde eski yapıların onarılması, iskan işleri, parkların düzenlenmesi, kaldırımların yeşillendirilmesi, camilerin tadilatı ve özellikle harap durumdaki mimari yapıların iyileştirilmesi konularındaki haberler hemen her yıl Yeşilgiresun Gazetesi'ne konu edilmiştir. Dönemin zorlu ekonomik koşullarının da etkisiyle bu yıllarda mekansal haberlerin büyük çoğunluğu yeni mimari yapıların inşasından çok var olanların düzenlenmesi ve kentin genel görünümünün güzelleştirilmesi odaklıdır. Gazetede “Güzelleşen Giresun" başlı̆̆ıyla kaleme alınan haberler kentin çehresinin değişmesinden duyulan memnuniyetin göstergesidir. Ancak 1938-1940 aral1ğındaki mekan haberlerinin büyük bir bölümü 1938 Erzincan depreminin kentte yarattığ 1 tahribat, hasar görmüş ya da yıkılmış yapılar üzerinedir. Bu haberler aslında gerek konumu gerekse mimari, mekansal ve işlevsel özellikleri ile Cumhuriyet' in sembolik yapılarından birisi olarak 1949'da inşa edilecek Giresun Belediyesi Hizmet Binası'nın inşasına zemin hazırlayacak haberlerin başlangıcını işaretler. Aynı zamanda bugün Giresun Üniversitesi Rektörlük Binası olarak kullanılan ve 19. yüzyıl Osmanlı modernleşmesinin kentteki temsillerinden sayılan Hükümet Konağı'nın ve Askeri kışlanın tamirine ilişkin haberler; güzel kent anlayışının yansımalarıdır.

Modern, sağhlklı kent yaklaşımı; Savaş sonrası Anadolu kentlerinin genelinde olduğu gibi Giresun'da da yollar bakımsız, alt yapı hizmetleri yetersizdir. Söz konusu yıllarda Bilgin' in (1998, s.257) belirttiği gibi ulaşımın, pis ve temiz suyun, elektriğin, haberin, bilginin kesintisiz dolaşımını sağlayacak bir sirkülasyon şebekesinin oluşturulması modern mimarlık ve kentleşme girişimlerinin temel konulardan birisi olmuştur. Cumhuriyet'in ilanının ardından, özellikle araştırma aralığının ilk yıllarındaki mekan haberlerinin modern yaşama uygun sağlık koşullarının sağlanması, temel mekansal gereksinimlerin karşılanması, kent içi-kent dışı yolların iyileştirilmesi ve düzenlenmesine ilişkin oldukları izlenmiştir. Yeşilgiresun Gazetesi'ndeki bu haberlerin bir bölümü halkın talep ve ihtiyaçlarını eleştirel bir dille gündeme taşırken bir bölümü kent içindeki yolların parke döşenmesi, tadilatı; parkların ıslah edilmesi gibi belediye odaklı alt yapı çalışmalarını konu edilmiştir.

Modern, sosyal yaşam düzeni, Cumhuriyet dönemi parkları kentlilik bilincini ve kültürünü pekiştiren, modern sosyal yaşam düzenini sunan mekanlar olarak önemsenmiş ve kent imgesi şeklinde konumlanmıştır. Yeşilgiresun'da mevcut parkların güzelleştirilmesi, eksikliklerinin giderilmesi ve yenilerinin açılması (Şekil 2) modern, güzel kent anlayışının mekansal ifadesi olurken aynı zamanda yeni bir sosyal yaşam düzenini örneklemektedir. Gazetedeki 1935, 1940 yıllarında bir spor sahası ihtiyacına, 1938'de tiyatronun 
mekansal durumuna, 1940'da Taşbaşı Parkı'nda kurulan açık sinemaya ilişkin haberler, kentte oluşturulması amaçlanan modern, sosyal yaşamın izlerini taşımaktadır. 1932'de bakımsızlığı nedeniyle gazeteye konu olmuş tenis bahçesinin korunması gerekliliği yönündeki haberler hem kentteki sosyal yaşam düzeninin hem de Osmanlı́nın son döneminde başlamış modernleşme öyküsünün göstergeleridir.

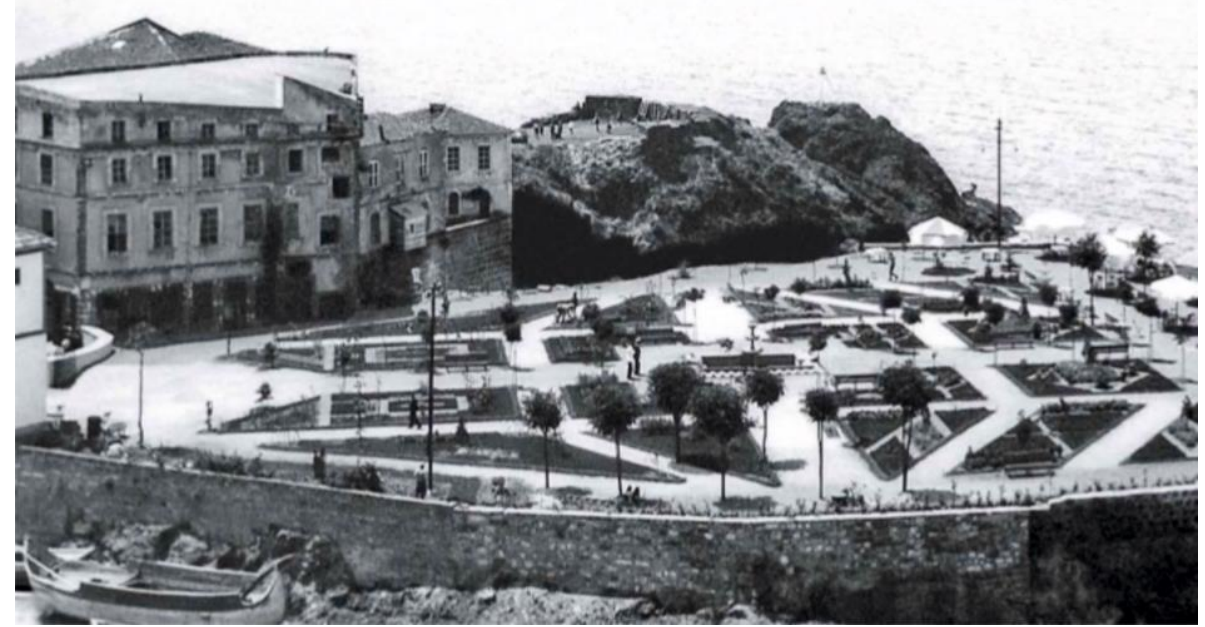

Şekil 2. Taşbaşı Parkı (Kaynak: Işık ve Dervişoğlu, 2011, s.127)

Ĕ̆itimde modernleşme; Althusser' in belirttiği gibi, okullar hakim ideolojik aygıtların en önemli göstergelerinden birisidir (Althusser, 2016, s.36). Bu bakışla, işleyen bir eğitim sisteminin oluşturulması, okuma yazma oranının arttırılması ve kırsaldan kente Anadolu'nun eğitim yapılarıyla donatılması ideolojinin bütüncül modernleşme yaklaşımının ilk adımı olarak görülmüş ve önemsenmiştir. Bu nedenle çalışmanın odaklandığı on yıllık dönemin her y1lında eğitimde modernleşmeye ilişkin haberlerin yer aldığı izlenmiştir. Cumhuriyetin ilk yıllarında değişen eğitim sisteminin ihtiyaç duyduğu yapılar diğer kentlerle benzer şekilde emval-i metruke binaları ile karşılanmaya çalışılmıştır. Dolayısıyla bu yıllardaki haberlerde çoğunlukla mevcut okulların Gazipaşa, Yeşil Giresun, İsmetpaşa- mekansal gereksinimleri ya da tadilatı konu edilmiştir. Bu müdahaleler ideolojik bakışla övülürken geçen süreçte bir lise binasının kentte inşa edilmemesi sıklıkla tekrar edilmiş, çocukların farklı kentlere yatılı gitme zorunlulukları eleştirilmiştir. Çalışma kapsamında incelenen yıllarda gazetede "Her sene kalplerimizi delen duygu: lise, lise, 
lise" şeklindeki haberlerin sürekli devam etmesi geçen süreçte sorunun çözülememiş olduğunu göstermektedir. 1939'da "On dershaneli modern okul" şeklindeki haber başlığı bugün "Cumhuriyet İlkokulu" olarak bilinen "Yeni Okul"un inşasını haber vermektedir. Gazetede modern mimarinin kentteki ilk temsilleri arasında yer alan okulun inşası büyük bir coşkuyla duyurulmuş, yapının inşa süreci ve açlış haberleri eğitimde modernleşmenin göstergeleri olarak vurgulanmıştır.

Sağlıkta modernleşme; Yeşilgiresun'da 1930'dan 1940'a sıklıkla tekrar edilen mekan haberlerinin başında kentin bir hastane yapısına duyduğu ihtiyacın, bir hastane krokisinin ve inşa sürecinin konu edildiği haberler gelmektedir. Çınarlar Mahallesi'ndeki Jandarma Mektebi'nin arka sokaklarından birinde yer alan ve kentin tek hastanesine -Memleket Hastanesi- alternatif yeni ve modern bir hastane ihtiyacını konu alan haberlerin 1938'de karşılık bulduğu ve hastanenin temellerinin atıldığı görülmektedir. Bu süreçte mevcut hastanenin ihtiyacı karşılayamadığına ve yeni bir hastane gerekliliğine yönelik haberler güçlü bir gündem yaratmıştır. "Kutlu Gün: Hastanenin temel atma töreni yüzlerce halkın iştiraki ile yapıldı" şeklinde habere konu olan hastane binası uzun yıllar kentte Doğum Hastanesi olarak kullanılan yapıdır. Hastane ihtiyacı haberlerinin gazetedeki sürekliliği kentte sağlık koşullarının iyileştirilmesi çabasını, halk sağlığının devlet meselesi olarak görüldüğünü ve merkezi otoritenin kentteki ihtiyacı karşılamaya yönelik önceliğini göstermesi açısından önemlidir.

Ulaşımda modernleşme; Cumhuriyetin kurulmasıyla ulaştırma konusu çok yönlü şekilde ele alınmış, önceliğin demiryolu ulaşımına verilmesine karşın denizyolu olanaklarının geliştirilmesine ve karayollarının iyileştirilmesine çalışılmıştır. Cumhuriyetin ilk yıllarında Yol Kanunu çıkarılmış, Nafıa Vekaleti bünyesinde Şose ve Köprüler Reisliği tarafından inşa çalışmaları yürütülmüş̧ür. Bu kapsamda kent içindeki yolların iyileştirilmesi ve düzenlenmesi modern, sağlıklı bir kentin gerekliliği olarak görülmüş, küçük ölçekli olsa da inşa faaliyetleri gazetede haber olmuştur. Gazetenin hemen her y1lında sahil yollarının ve köprülerin tadilatına, açllan yeni yollara ve köprülere ilişkin haberlere rastlanır. Kentin ticari olarak kalkınmasında ve ulaşılabilirliğinin artmasında etkili olacak mevcut rıhtımın yeni bir limana dönüştürülmesi, eksiklerinin giderilmesi, önüne bir dalgakıran inşa edilmesi haberleri aynı eksende okunabilir. Bu bakışla ulaşımda modernleşme iktisadi kalkınmanın da öncüsü olarak kabul edilmelidir. Dolayısıyla Yeşilgiresun'daki rıhtım ve liman haberleri hem iktisadi kalkınmanın hem de ulaşımda modernleşmenin ideolojik göstergeleridir. 
Toplumsal dönüşüm; Cumhuriyet ideolojisinin hedeflediği toplumsal dönüşümün sağlanması amaciyla Anadolu kentleri, öncesinde görülmemiş uygulamalara sahne olmuştur. Yeşilgiresun Gazetesi'nin 1930'dan 1940'a kadar ki kimi sayılarında; kentte düzenlenen Yılbaşı Balosu, Tayyare Balosu, Cumhuriyet Balosu, Çocuk Balosu ve müsamere gibi etkinlikler kadınların ve erkeklerin modern, şık kıyafetlerle bir arada bulunduğu, kollektif ve seküler bir toplum düzeninin örnekleri olarak konu edilmiştir. Gazetedeki haberler kronolojik olarak incelendiğinde büyük bir coşkuyla kutlanan bu etkinliklerin belli bir rutin içerisinde tekrar ettiği anlaşılmaktadır. Bu etkinlikler dışında "Garden Parti" adıyla Küçükyalı Parkı'nda (Şekil 3) düzenlenen toplantı ve kutlamalar modern yaşamın göstergeleri kabul edilmiş, İngilizce anlamı ile gazetede sunulmuştur. Modern yaşam ritüelleri olarak kent yaşamını yönlendiren batı kökenli bu etkinlikler çoğunlukla halkevinin desteğinde gerçekleştirilmiş ve gazetede olumlu bir bakışla kaleme alınmıştır. Öte yandan kültür ve sanat etkinliklerinin yıldan yıla artması şehir kulübü ihtiyacının gündeme getirmiş ve bu konu gazetede sıklıkla vurgulanmıştır.

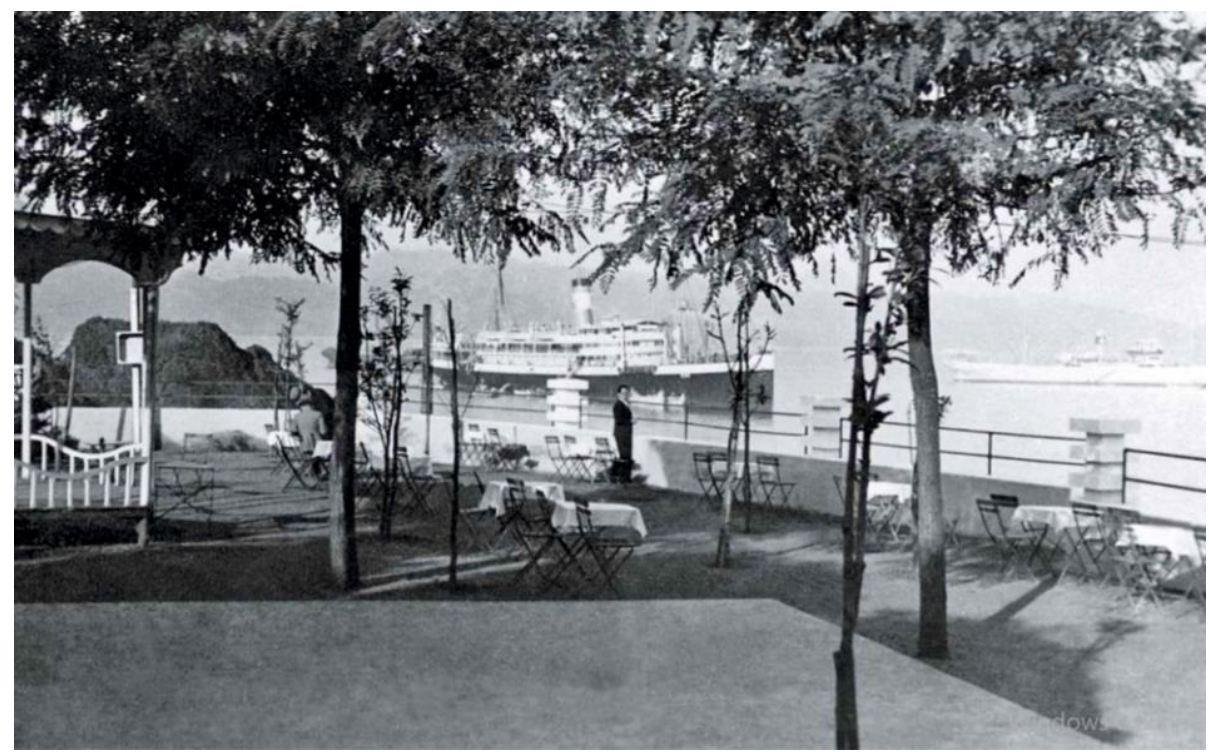

Şekil 3. Küçükyalı Parkı (Kaynak: Işık ve Dervişoğlu, 2011, s.119)

Kolektif temsili ideoloji; Cumhuriyet' in ilanıyla devletin kendine ait yeni bir kolektif kimlik oluşturma ihtiyacı doğmuştur. Kolektif kimlik Cumhuriyet'in farklılığını ortaya koymakta ve aidiyet, bilinç, duygu ve tekilliğini yansitmaktadır. Bu kapsamda, merkezden periferiye Anadolu kentlerinde 
kolektif ve temsili bir kimlik yaratmanın aracı olarak Atatürk heykelleri, meydanlar ve antlar inşa edilmiştir. Bu nedenle 1936, 1937, 1938 yıllarında gazetede yer alan, kentte bir Atatürk heykeli inşasının planlandığı yönündeki haberler kolektif ve temsili ideolojinin göstergeleri olarak kabul edilebilir. Cumhuriyet kutlamalarının ve törenlerinin düzenlendiği, başlangıçta Osman Ağa Meydanı olarak bilinen sonrasında Cumhuriyet Meydanı olarak düzenlenen alana ilişkin haberler sıklıkla gazeteye konu edilmiştir (Şekil 4). Cumhuriyet Meydanı inşasını takip eden yıllarda toplumsal biraradalık sağlayan sembolik mekanlardan birisi olarakvarlık göstermiş, ideolojik anlamını ve gücünü yıldan yıla pekiştirmiştir. İdeolojinin kentteki tanıklarından 10. Y1l Anıtı, Cumhuriyetin ilanının 10. yllı anısına inşa edilmiştir. Cumhuriyet Meydanı içerisinde görece yüksek bir alanda konumlandırılan anıt, meydandaki varlığı ile iktidarın ideolojik söylemini ve gücünü sembolize etmiştir.

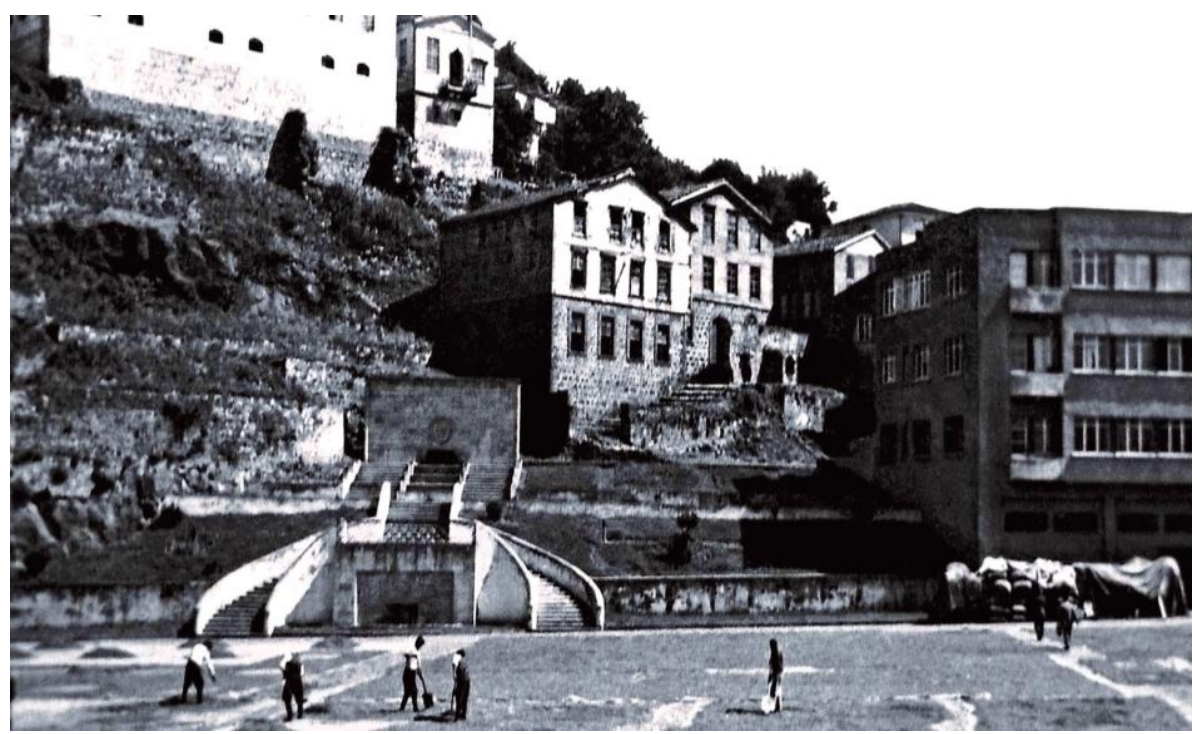

Şekil 4. Cumhuriyet Meydanı ve 10.yıl Anıtı (Kaynak: Işık ve Dervişoğlu, 2011, s.227)

Millileşme/Milli Kültür, Cumhuriyet modernleşmesinde dil inkılabının özel bir yeri bulunur. İdealize edilen toplumsal kimliğin yerleşmesinde, millileşmenin sağlanmasında özgün ve sadeleştirilmiş milli bir dilin önemi vurgulanmış (Yıldırım, 2018, s.321), bunun güçlendirilmesi amacıyla ulusal ölçekte Dil Bayramı kutlanmaya başlanmıştır. Yeşilgiresun'da da bir modernleşme ve millileşme hareketi olarak kentteki Dil Bayramı kutlamalarına vurgu yapıldığı izlenir. Giresun halkevi tarafından 1933'te yayımlanmaya başlanan Aksu Dergisi hem içeriği hemde kullandığı akıcı Türkçe ile yerel 
kültüre vurgu yaparak halka moderni anlatmıştır. Aksu Dergisi'nin ve Dil Bayramı'nın kentteki kültürel hayatı besleyerek ortak bir hafıza oluşturduğu ve milli kültüre katkı sağladığı söylenebilir. Bu anlamda yerele vurgu yapan içeriğiyle Aksu Dergisi, modern-kentli bilincini geliştiren bir araç olarak uzun yıllar yayın hayatını sürdürmüştür.

Toplumsal birlik/Ulusal kimlik; Cumhuriyet ideolojisinde ulusçuluk, belirli sınırlar içerisinde kültür ve kader birliği yaşayan insanları kapsayarak "millet olma"yı pekiştirmiştir (Yıldırım, 2018, s.318). Toplumsal birlik ve ulusal kimlik oluşturma çabası Cumhuriyet' in hedeflerinden biri olarak kabul edilirken kentlileri bir araya getiren ve ulus olma bilincini aşılayan gerek ulusal gerekse yerel ölçekli kutlamalar ve bayramlar büyük bir coşkuyla kutlanmıştır. Mayıs Yedisi, Hıdırellez ve ilk kez 1933’de düzenlenen Fındık Bayramı (Şekil 5) kentte gerçekleştirilen yerel kutlamalardır. Fındık Bayramı fındığın sadece tarımsal bir ürün olarak iktisadi öneminin ötesinde kültürel hayattaki anlamını ve değerini göstermesi açısından kentli tarafından önemsenmiş ve coşkuyla karşılanmıştır. Yeşilgiresun'da periyodik olarak sürdürülen kutlamalara ilişkin övgü dolu haberlere sıklıkla yer verilmiştir.

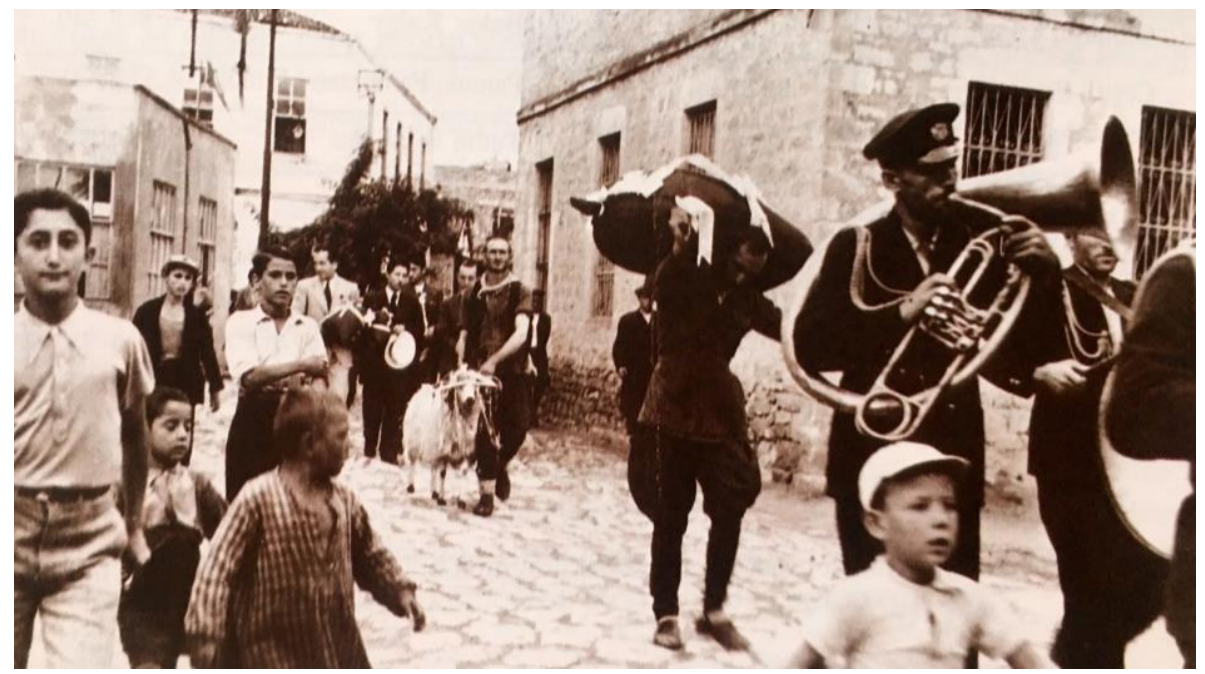

Şekil 5. Fındık Bayramı kutlamaları (H. Gazi Menteşoğlu, t.y)

Modern işlevler ve mekansal çeşitlilik; Cumhuriyetin ilanı ile kentte başlayan dönüşüm, kentsel mekanın yenilenmesinin yanı sıra mekansal eksikliklerin tamamlanmasını içeren çalışmalara zemin hazırlar. Yeşilgiresun'da kamu yapıları dışındaki işlevlerin gerektirdiği yapılara duyulan ihtiyaç ve inşa haberleri, kentteki modernleşme deneyiminin bir parçasıdır. Modern 
kentlerin işlevsel çeşitliliği içerisinde yer alan ve gelişen ticari faaliyetleri destekleyici bir Evkaf Oteli'nin kente kazandırılması haberleri bu kapsamda değerlendirilebilir. Bir kamu yapısı olmasına karşın postane binası kentteki mekansal çeşitliliğin bir diğer yapısıdır. Bu yapının hem inşası hem de "Giresun'da ilk kübik bina: postane" şeklinde habere konu oluş biçimi dönemin mimari eğilimlerinin kentteki yansımasını göstermesi açısından önemlidir. "Kübik mimari" tanımlaması, dönemin modernlik kültürünün biçimsel önyargılarının bir göstergesidir (Bozdoğan, 2008, s.74) ve postane binasının modern mimari özelliklerini vurgular (Şekil 6). Aynı şekilde inşası planlanan mezbahanenin "modern bir mezbahane" başlı̆̆ ile sunulması hem kentte modern işlevlere duyulan ihtiyacın hem de sağlıklı kent anlayışının Yeşilgiresun gazetesindeki yansıması olarak değerlendirilebilir.

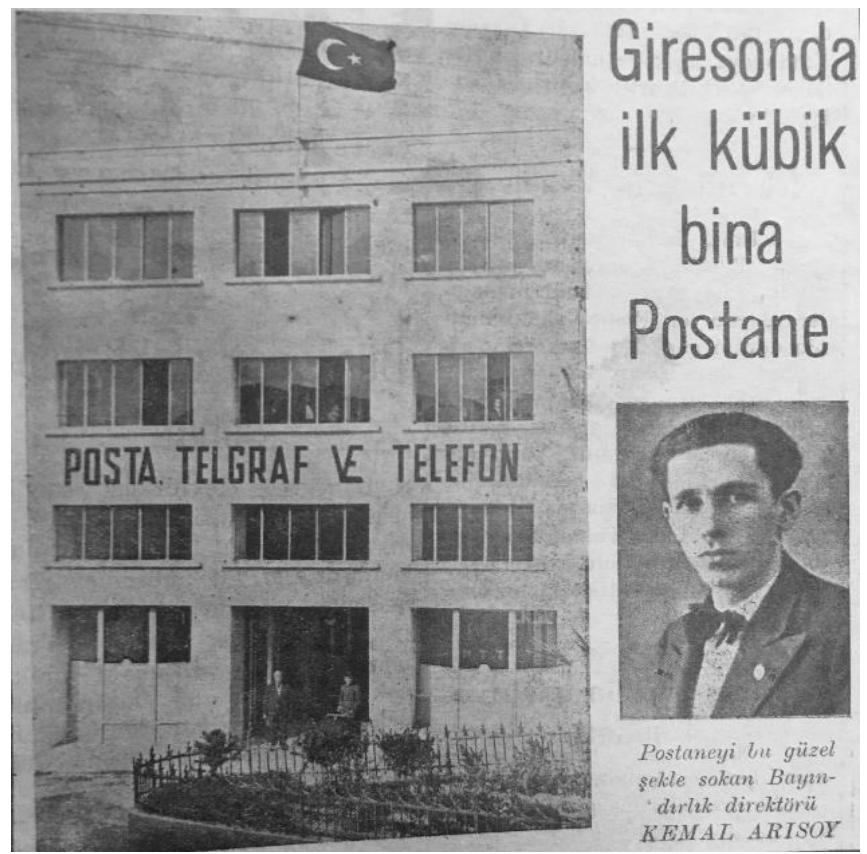

Şekil 6. Yeşilgiresun' da postane binası inşa haberi (Yeşilgiresun Gazetesi Arşivi, 1936)

İktisadi kalkınma; Devletin iktisadi kalkınma hedefi gazete haberlerinde sunulan bir diğer ideolojik yaklaşımdır. Yeşilgiresun'da tarımsal bir ürün olarak fındık üreticilerini destekleyecek, bölgesel işbirlikli bir Fındık Bankası'nın kurulmasına ilişkin haberlerin iktisadi kalkınmanın kentteki yansımaları olarak okunması mümkündür. Bu kapsamda 1930'da Tuğla Fabrikası'nın inşasına, 1935 'te yeni bir Gümrük binasının gerekliliğine ve bir is- 
kelenin inşa edileceğine ilişkin gazetede yer alan haberler kentte ticari faaliyetlerin arttı̆ını göstermektedir. Yeşilgiresun'da kentteki mekansal eksikliklere ilişkin, özellikle sağlık, eğitim hizmetlerini ve ticari faaliyetleri etkileyecek haberler eleştirel bir dille yinelenmiştir. Bu süreklilik içerisinde önce iskelenin, sonra rıhtımın iyileştirilmesine ve en nihayetinde bir liman ihtiyacına yönelik haberler kentteki iktisadi kalkınmanın göstergeleridir. Konunun halk tarafından ne kadar önemsendiği gazetede yer alan "Bir mendirek bile hak etmedik mi?" şeklindeki eleştirel söylemle desteklenir.

Devletin kimlik inşası; Cumhuriyetin ilanının ardından Anadolu genelinde sürdürülen devletçi yaklaşım erken Cumhuriyet döneminde kentlerdeki inşa faaliyetlerini ivmelendiren en temel güçtür (Tekeli, Şeylan, 1978, s.78). Giresun'da Osmanlı'nın son çeyreğinde başlayan modernleşme deneyimi mimari ve kentsel mekanın değişimini, yenilenmesini ya da eksikliklerinin tamamlanmasını içeren bir dizi uygulama ile devam ettirilmiştir. Bunların tamamı devlet tarafından halka büyük bir coşkuyla sunulurken Yeşilgiresun Gazetesi'nde de aynı övgü ve memnuniyetle konu edilmiştir. 1933'de "On senelik Cumhuriyet devrinde Giresun”, 1938'de "Yükselen eserler karşısında" ve "15 yıl içinde Giresun'da vücuda gelen hizmetler" şeklindeki haberler Cumhuriyet'in kent mekanındaki ideolojik varlığını yüceltmiştir. Yeşilgiresun'da eğitim yapıları, hastane, postane, cezaevi ya da yolların inşası ve iyileştirilmesi yönündeki her türlü imar faaliyeti ve belediyecilik hizmeti kentin kazandığı modern çehrenin parçalarıdır.

Yerel kalkınma; Cumhuriyet modernleşmesi yerel gerçekliklerle karşılaşarak çok katmanlı bir görünüm kazanmış ve yeni bazı modeller üzerinden devlet eliyle yaşama geçirilmiştir (Arıtan, 2008, s.49-56; Bozdoğan, 2002, s.114-121). Tarımsal üretimin artması ve ürünlerin katma değerlerinin artırılması amacıyla kurulan kooperatifler bu modellerin bir örneğidir. Bu kapsamda 1938'de kurulan Fiskobirlik kentin iktisadi ve mekansal gelişiminin destekçisi olmuştur. 1939'da gazetede inşası konu edilen fındık laboratuvarı (Şekil 7) ve kent merkezinde Fiskobirlik tarafından inşa edilen 1. Nolu Fındık Kırma Fabrikası (Şekil 8) yerel kalkınma hedefinin desteklendiğini ve önemsendiğini göstermektedir. Gerek Ziraat Nezareti (Bakanlığı'na) bünyesinde kurulan Fındık Araştırma İstasyonu'nun gerekse Fiskobirlik bünyesinde kurulan Fındık Kırma Fabrikası'nın gazete haberlerine konu olması, halkın temel geçim kaynağı olarak fındığa verdiği önemi ve yerel kalkınmanın aracı olarak kabul ettiğini gösterir. Zamanla sermayesini ve etkinlik alanını büyüterek bölgesel bir üretici birliğine dönüşen kooperatifin ilk 
büyük fabrika yapısı olarak 1. Nolu Fındık Kırma Fabrikası ve Fındık Laboratuvarı, öncü olma özellikleriyle kentin kollektif belleğindeki yerini korumaktadır (Demirkan, Karaibrahimoğlu, s.872)

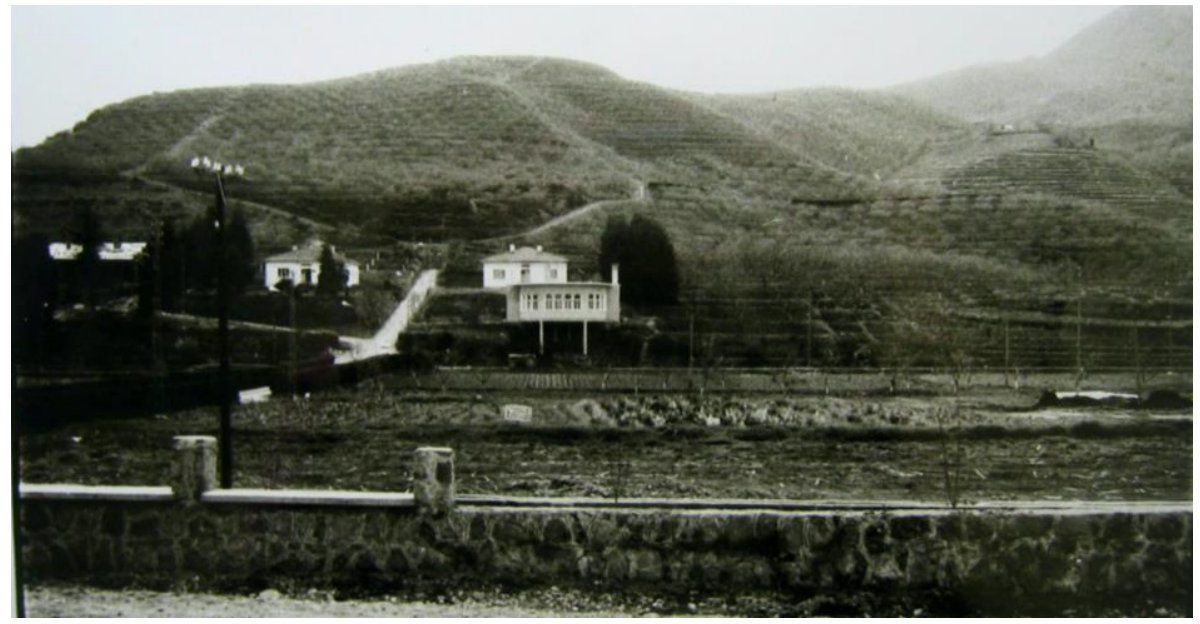

Şekil 7. Fındık Laboratuvarı (Fındık Araştırma Enstitüsü Müdürlüğü, t.y)

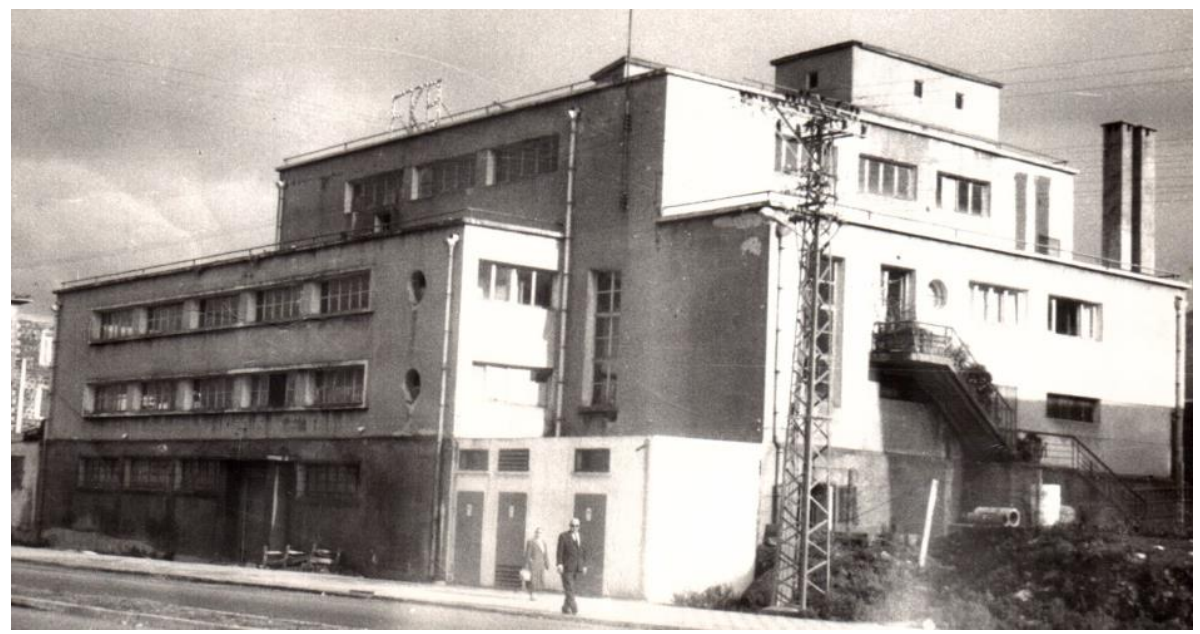

Şekil 8. 1.Nolu Fındık Kırma Fabrikası (H. Gazi Menteşoğlu, t.y)

Yeni yaşamın göstergeleri; Cumhuriyetin öngördüğü modern yaşam düzenini halka sunan ve anlatan ideolojik birer araç olarak kültürel faaliyetlerinin tamamı desteklenmiş, etkinliklerini artırarak sürdürülmeleri sağlanmıştır. Bu kapsamla kültürel etkinliklerin sıkça Yeşilgiresun'da konu edildiği izlenmektedir. Haberler, kentte gerçekleştirilen sinema gösterimleri, tiyatro toplulukları, sergilerin zamanla arttığını ve nitelik olarak 
çeşitlendiğini gösterir. Kentin yerel kaynakları ile düzenlenen kültürel etkinlikler belli bir süreklilik içerisinde devam ettirilmiş, etkinliklere ilişkin haberlere gazetenin hemen her sayısında periyodik olarak yer verilmiştir. Ayşe Opereti, İstanbul Opereti ya da Sümer Orkestrası (Şekil 9) gibi merkezi temsil eden İstanbul-Ankara kökenli etkinlikler de övgüyle gazeteye haber olmuştur. Ayrica gazetede yer alan şehir kulübüne ve çocuk tiyatrosuna ilişkin haberler, halkevleri dışında bir kültür mekanı ve etkinlik alanı arayışını yansıtmaktadır.

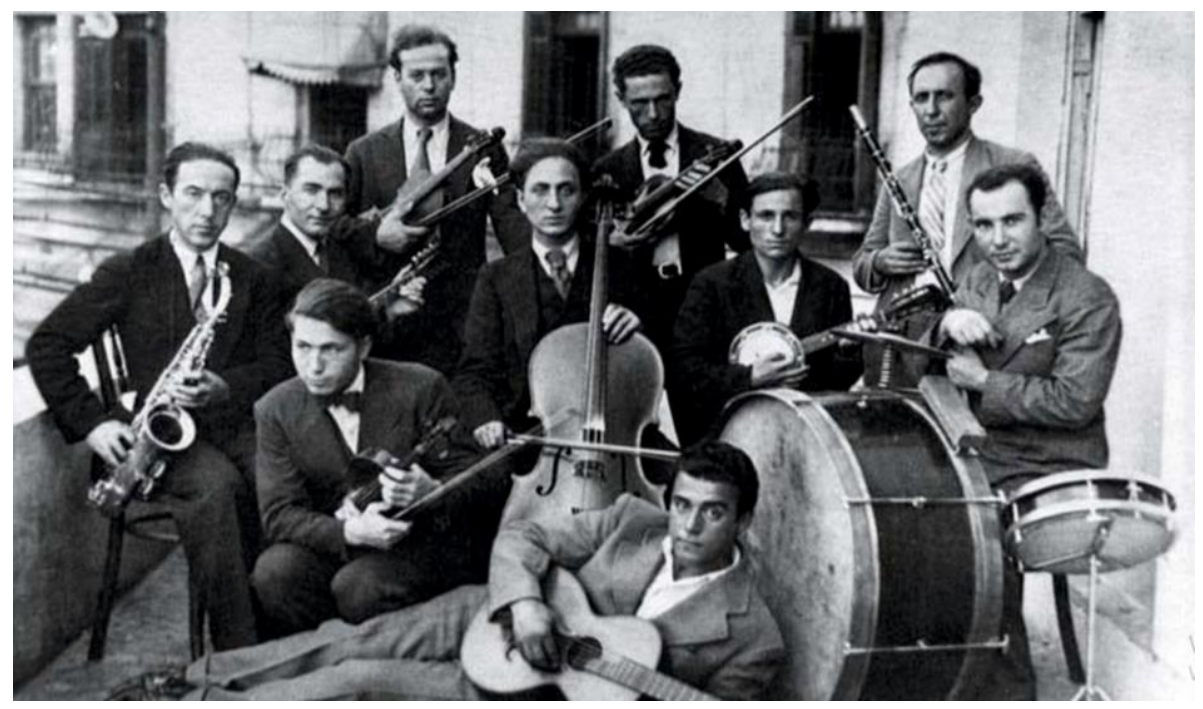

Şekil 9. Giresun'da Sümer Orkestrası (1938) (Işık ve Dervişoğlu, 2011, s.417)

Son olarak, haberlerin 1930-1940 aralığında ylldan ylla gazetedeki dağılımı değerlendirildiğinde (Tablo 3) modern, güzel ve sağlıklı bir kent oluşturma, ulaşımda modernleşmeyi sağlama, hem mekansal hem de sistemsel olarak eğitimde modernleşmeyi sağlama ideallerine ilişkin haberlerin hemen hemen her sayıda yer aldığı açıkça izlenebilmektedir. Kentin imarından ve halkın eğitiminden sonra önem verilen bir diğer konu halkın sağlı̆̆ olmuştur. Sağlıkta modernleşme ideolojisinin kent mekanındaki yansımaları özellikle 1933-1938 yılları arasında yoğunlaşmıştır. Yeşilgiresun'a göre 19321940 yılları ulusal ölçekli iktisadi kalkınmanın desteklendiği yıllardır. Ancak yerel kalkınma hedefleri her zaman kent gündemindeki yerini korumasına karşın belli aralıklar ile gazeteye konu olmuştur. Kolektif bir kimliğin inşası amacıyla gerçekleştirilen uygulamalar ve devletin kentteki kamu yatırımları 1936 sonrasında yoğunlaşmaktadır. Buna karşın tüm yıllarda gazetede kentin kültür hayatıyla ilgili haberler periyodik olarak yer almakta; toplumsal 
dönüşüm, halkın eğitimi ve pozitivist bilimin üstünlüğünü sağlamayı hedefleyen, yeni bir yaşam şeklini örnekleyen etkinlikler yoğunlaşmaktadır.

Tablo 3. Yeşilgiresun' da yıllara göre anlamsal çözümleme

\begin{tabular}{|c|c|c|c|c|c|c|c|c|c|c|c|}
\hline & 1930 & 1931 & 1932 & 1933 & 1934 & 1935 & 1936 & 1937 & 1938 & 1939 & 1940 \\
\hline \multicolumn{12}{|c|}{ Modern/Güzel kent yaklașımı } \\
\hline \multicolumn{12}{|c|}{ Modern/Sağlıklı kent yaklașımı } \\
\hline \multicolumn{12}{|l|}{ Eğitimde modernleşme } \\
\hline \multicolumn{12}{|l|}{ Ulaşımda modernleşme } \\
\hline \multicolumn{12}{|l|}{ Sağhkta modernleşme } \\
\hline \multicolumn{12}{|l|}{ Yerel kalkınma } \\
\hline \multicolumn{12}{|l|}{ Devletin kimlik inşası } \\
\hline \multicolumn{12}{|l|}{ İktisadi kalkınma } \\
\hline \multicolumn{12}{|c|}{ Modern sosyal yaşam düzeni } \\
\hline \multicolumn{12}{|c|}{ Modern işlevler ve mekansal çeşitlilik } \\
\hline \multicolumn{12}{|l|}{ Kollektif temsili ideoloji } \\
\hline \multicolumn{12}{|l|}{ Devletin kimlik inșası } \\
\hline \multicolumn{12}{|l|}{ Toplumsal dönüșüm } \\
\hline \multicolumn{12}{|c|}{ Halkın Eğitimi/Pozitivist bilimin üstünlüğü } \\
\hline \multicolumn{12}{|c|}{ Yeni bir yașamın göstergeleri } \\
\hline \multicolumn{12}{|c|}{ Toplumsal birlik/Ulusal kimlik } \\
\hline Millileşme/Milli kültür & & & & & & & & & & & \\
\hline
\end{tabular}

\section{Sonuç}

Giresun kent mekanı, Cumhuriyet' in ilk yıllarında Anadolu'nun neredeyse tamaminda temelde modern kent düzeni kurma amaçlı sosyal, mekansal ve ekonomi odaklı reformların etkisiyle biçimlenmiştir. Yeşilgiresun Gazetesi, kentin bu ideolojik yönelimini destekleyecek bir yayın politikası sürdürürken haberler kimi zaman dönemin şartlarının sonucu olarak eleştirel bir söylemle sunulsa da çoğunlukla Cumhuriyet'in öngördüğü mekansal ve kültürel müdahaleler övgüyle anlatılmıştır. Bu anlamda Yeşilgiresun Gazetesi Anadolu'nun kıyı kentlerinden biri olan Giresun'da Cumhuriyet ideolojisi eksenli modernleşme deneyimini büyük bir tutarlılıkla anlatan kapsamlı bir içeriğe sahiptir. Dolayısıyla Yeşilgiresun'un kendisi de modernist, yenilikçi bir temsiliye sahiptir. Gazetenin odağındaki haber başlıkları zamansal olarak farklılık barındırsa da Cumhuriyet ideolojisinin modern yüzünü yansıtmaktadır. Yeşilgiresun'da yer alan mekan ve kültür haberleri; bir ulusun yeniden inşasını yönlendiren ideolojiyi ve bileşenlerini algılanabilir, kentteki izleri ise gözle görülebilir ve dokunulabilir kılmıştır. 


\section{Extended Abstract}

\section{Tracing the Republican Ideology in the City; Culture, Place and Meaning in Yeşilgiresun Newspaper}

\author{
Özgür Demirkan \\ ORCID: 0000-0001-5430-1018
}

\author{
Selin Karaibrahimoğlu \\ ORCID: 0000-0002-0941-8185
}

Giresun, which gained the status of a province after the proclamation of the Republic, transformed gradually from a small Ottoman district that continued its development through agricultural production into a city where new structures such as banks, educational buildings, health institutions, parks and squares and new spatial arrangements began to take place as the object of the modern urban order and the Republic's ideology. During this period, the artistic and cultural activities carried out in the city supported the modernization experience in the city, and, in particular, the conferences, performances, cinema, and theater activities organized by the community centers became the means of internalizing and popularizing modern life. For this reason, it can be said that the ideology of modernization was realized in the city in a partnership with space and culture, and its continuity was ensured. This multifaceted partnership was effective in determining the method of the study. Thus, apart from studies that attempt to explain the Republican ideology by positioning it in the architectural literature of the central cities, periphery-oriented studies were also added to the city and history literature, thus enriching the understanding of the period.

The temporal focus of this study is the period 1930-40, which is accepted as the second period of Anatolian modernization in periodic evaluations that are frequently followed in studies on the modernization process in Anatolia. For Giresun, it is observed that this period gained importance as a period in which attempts were made to spread the Republican ideology, carries striking traces of human-oriented transformation, and ideological reversals were being followed. In this study which is built on two layers within this scope, first, the news headlines in the Yeşilgiresun newspaper were scanned with a focus on 
space and culture in parallel with the temporal changes, Among all the news headlines in the newspaper between 1930 and 40, location and cultural news were selected and listed in chronological order according to the date of publication. Later, in order to make a relational reading regarding the cooperation of culture and space, an attempt was made to interpret the scanned news using semiotic analysis, thus allowing a search for the spatial traces of the Republic ideology in the city. As a result, it was determined that most of the news in the said period was focused on public buildings constructed or planned for different functions and purposes; and the municipality was active in all development activities as an organization serving as well as representing local actors, and the governorship was active as an organization supervising related agencies and representing the central government. The work on the infrastructure, water, sewage, roads and bridges, cadastre, and the preparation of a development plan for the city, which are included in the application area of municipal services, were followed by the construction of new public buildings, and most of the news on housing remained at the level of hovels and abandoned residences. Cumhuriyet Square and the 10th Anniversary Monument, Taşbaşı Park, the Findık Laboratory and the Hazelnut Crushing Factory, the hospital, Cumhuriyet Primary School, the post, and the slaughterhouse are the structures that can be described as the spatial traces of ideology in the city. While some of these structures visually nurture the symbolic power of ideology in the city, some of them have become spatial expressions of the changing administrative order, living conditions, and economic development. The existence of these structures, functional or spatial transformation processes, the course of development in cultural field can be followed through the readings regarding the partnership of culture, space, and meaning in Yeşilgiresun as a local newspaper.

The fact that there is news about the cultural life of the city in almost every issue of Yeşilgiresun reflects the social change experienced by the young republic in a short time. On the other hand, this study which makes sense of a local newspaper as an important part of the city's memory and culture, apart from local historical research or city archives, offers a different approach by showing that it is possible to trace the central spatial and cultural discourses in peripheral cities through local newspapers through the lens of the Yeşilgiresun newspaper.

\section{Kaynakça/References}


Althusser, L. (2016). İdeoloji ve devletin ideolojik aygıtları. 5. baskı, (A. Tümertekin, Çev.), İstanbul: İthaki Yayınları.

Arıtan, Ö. (2008). Modernleşme ve Cumhuriyet'in kamusal mekân modelleri. Mimarlık, 342, 49-56.

Artan, Ö. ve Sayar, Y. (2009). İzmir Sümerbank basma sanayi yerleşkesi ve dönüşüm süreçleri. Ege Mimarlik, 3 (70), 20-25.

Avar, A. A. (2009). Lefebvre'în üçlü-algilanan, tasarlanan, yaşanan mekân-diyalektiği. F. Doğan (ed.), Mimarlık ve Mekan Algısı içinde (s.7-16), Ankara: Mimarlar Odası Ankara Şubesi Yayınları.

Aydınlı, S. (1996). Türkiye'de mimarlık ve ideoloji: Ontolojik sorgulama. İdeoloji, Erk ve Mimarlık Sempozyum Bildirileri kitabı içinde (s.11-13), İzmir: Dokuz Eylül Üniversitesi Yayınları.

Ayhan, N. (2018). Simgesel yapilarda hegemonya ve ideolojinin inşası. İstanbul: Cinius Yayınları.

Bayrakç, O. (2011). Göstergebilimsel araştırma alanı olarak ürün tasarımı. Tasarım ve Kuram, 7 (11), 1-14.

Bilgin, İ. (1998). Modernleşmenin ve toplumsal hareketliliğin yörüngesinde Cumhuriyet'in imarı. Y. Sey (ed.), 75 Yılda Değişen Kent ve Mimarlık içinde (s.255-272), İstanbul: Türk Tarih Vakfı Yayınları.

Bozdoğan, S. (2008). Modernizm ve bir ulusun inşası. İstanbul: Metis Yayınları.

Çapa, M. (2003). Yeşilgiresun gazetesine göre Giresun' da millî gün kutlamaları ve Atatürk. Yeşilgiresun Gazetesine göre Cumhuriyet'in İk Yillarında Giresun içinde (s.1-12). Ankara: Ümit Yayıncılık.

Demirkan, Ö. ve Karaibrahimoğlu, S. (2018). Tarımsal bir ürün olarak findığın Osmanlı'dan Cumhuriyet'e kent mekanına yansımaları. İdealkent-Kent Araştırmaları, 25, 856-884.

Dervişoğlu, T. (2019). Sözlü görüşme. [Mülakat] Tuncer Dervişoğlu, 5 Haziran 2019.

Düzenli, E. (2009). Cumhuriyet dönemi'nde (1923-1960) modernite düşüncesinin mekansal kuruluşu: Merkez-periferi dinamikleri bağlamında Trabzon örneği. Yayınlanmamış doktora tezi, Karadeniz Teknik Üniversitesi, Trabzon.

Erkarslan, Ö. (2009). Yeşil-Yeşilimsi: Ürün göstergebilimi aracıllğıyla sürdürülebilir tasarım uygulamalarının eleştirisi. Mimarlık, 349, 75-79.

Erkman, F. (1987). Göstergebilime giriş. İstanbul: Alan Yayıncllı.

Erzen, N. J. (2016). Sanat, güç ve direniş. Dosya 37. Sanat ve Politika Ekseninde Mekan içinde (16-24), Ankara: Mimarlar Odası Yayınları.

Fındık Araştırma Enstitüsü Müdürlüğü (t.y). Fındık laboratuvarı. 2020, 13 Ekim tarihinde https://arastirma.tarimorman.gov.tr/findik/Menu/8/Tanitim adresinden erişilmiştir.

Giresonda ilk kübik bina Posthane, (1936, 17 Mart). Yeşilgiresun, s.1.

Hızlan, D. (2016). Bir taşra gazetesinin 100. yılı ya da taşranın belleği. Hürriyet. 3 Kasım 2019 tarihinde www.hurriyet.com.tr adresinden erişildi.

Işık, A., ve Dervişoğlu, T., (2011). Ey gidi Giresun, Giresun bedensel engelliler gençlik ve spor kulübü. Ankara: Özyurt Matbaacılık. 
Karaibrahimoğlu, S. ve Demirkan, Ö. (2019). Yeşilgiresun Gazetesi üzerinden dönemsel bir okuma; Giresun'da kent ve mimari (1945-1955). İstanbul: VI. Yıldız Uluslararası Sosyal Bilimler Kongresi bildiriler kitapçı̆̆̆.

Karaibrahimoğlu, S. ve Usta, A. (2018). Urban-Public area architecture as the object of the political ideology: Ankara example. International Journal of Architecture and Urban Studies, 3, 47-67.

Karpat, K. (2019). Osmanlı'dan günümüze kimlik ve ideoloji. İstanbul: Timaş Yayınları.

Lefebvre, H. (2014). Mekanın üretimi. (I. Ergüder, Çev.), İstanbul: Sel Yayıncılı.

Mardin, Ş. (2009). Türkiye'de toplum ve siyaset. İstanbul: İletişim Yayınları.

Mardin, Ş. (2018). İdeoloji. İstanbul: İletişim Yayınları.

Menteşoğlu, H. G. (t.y). 1 nolu fındık fabrikası. [Fotoğraf], H. Gazi Mente-şoğlu Kişisel Arşivi.

Menteşoğlu, H. G. (t.y). Findık bayramı kutlamaları. [Fotoğraf], H. Gazi Menteşoğlu Kişisel Arşivi.

Mora, N. (2008). Medya ve kültürel kimlik. Uluslararası Insan Bilimleri Dergisi, 4 (1), 1-14.

Öğütçü, H. (2019). Sözlü görüşme. [Mülakat], 28 Ekim 2019.

Parsa, S. ve Parsa, A.F. (2009). Göstergebilim çözümlemeleri. İzmir: Ege Üniversitesi İletişim Fakültesi Yayınları.

Peirce, C. S. (1994). Peirce on signs: Writings on semiotic. J. Hoopes (Der.), North Carolina: The University of North Caroline Press.

Rifat, M. (2013). Açıklamalı göstergebilim sözlüğ̈̈u. İstanbul: Türkiye İş Bankası Kültür Yayınları.

Saussure, F. (2014). Genel dilbilim dersleri. (B. Vardar, Çev.), İstanbul: İthaki Yayınları.

Tanyeli, U. (1998). Üç kuşak Cumhuriyet. U. Tanyeli (Ed.), Mekanlar, Projeler, Anlamlar içinde (101-107), İstanbul: Türkiye Ekonomi ve Toplumsal Tarih Vakfı Yayınları.

Tanyeli, U. (2015). Politika mı mimarlık üretir? Mimarlıkla politika mı üretilir?. Altüst Dergisi, 14, 30-34.

Tekeli, İ. (1998). Türkiye' de Cumhuriyet döneminde kentsel gelişme ve kent planlaması. Y. Sey (ed.), 75 Yılda Değişen Kent ve Mimarlık içinde (s.1-14), İstanbul: Türkiye İş Bankası Kültür Yayınları.

Tekeli, İ. ve Şaylan, G. (1978). Türkiye' de halkçlık ideolojisinin evrimi, Toplum ve Bilim Dergisi. 6 (7), 44-110.

Tüfekçioğlu, H. (1992). Cumhuriyet ideolojisi ve Türk basını. İstanbul Üniversitesi Sosyoloji Dergisi, 3, 45-96.

Van Dijk, T. (2019). İdeoloji: Multidisipliner bir yaklaşım. (A. Demir, Çev.), Ankara: Hece yayınları.

Yeşilkaya, N. G. (1999). Halkevleri: Ídeoloji ve mimarlı. İstanbul: İletişim Yayınları.

Yıldırım, S. (2018). Cumhuriyet döneminde bir çatı kavram olarak ulus ideolojisi ve bileşenleri. Kent Akademisi, 11 (33), 317-331. 